OAK RIDGE

NATIONAL LABORATORY

MANAGED BY UT-BATTELLE

FOR THE DEPARTMENT OF ENERGY

\title{
Smart Infrared Inspection System Field Operational Test
}

\section{June 2011}

Prepared by

Adam Siekmann

Gary Capps

Oscar Franzese

Mary Beth Lascurain

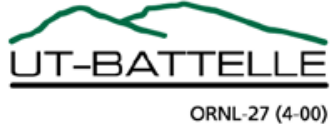




\section{DOCUMENT AVAILABILITY}

Reports produced after January 1, 1996, are generally available free via the U.S. Department of Energy (DOE) Information Bridge.

Web site http://www.osti.gov/bridge

Reports produced before January 1, 1996, may be purchased by members of the public from the following source.

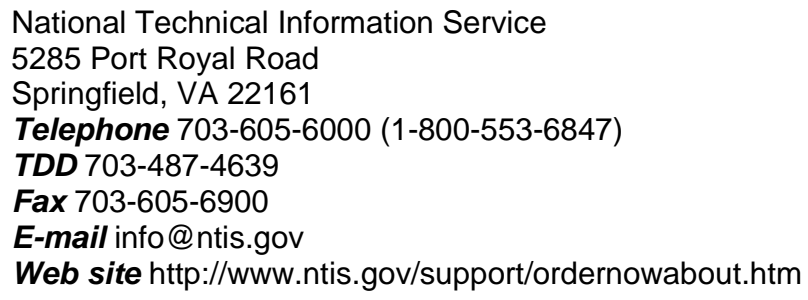

Reports are available to DOE employees, DOE contractors, Energy Technology Data Exchange (ETDE) representatives, and International Nuclear Information System (INIS) representatives from the following source.

Office of Scientific and Technical Information

P.O. Box 62

Oak Ridge, TN 37831

Telephone 865-576-8401

Fax 865-576-5728

E-mail reports@osti.gov

Web site http://www.osti.gov/contact.html

This report was prepared as an account of work sponsored by an agency of the United States Government. Neither the United States Government nor any agency thereof, nor any of their employees, makes any warranty, express or implied, or assumes any legal liability or responsibility for the accuracy, completeness, or usefulness of any information, apparatus, product, or process disclosed, or represents that its use would not infringe privately owned rights. Reference herein to any specific commercial product, process, or service by trade name, trademark, manufacturer, or otherwise, does not necessarily constitute or imply its endorsement, recommendation, or favoring by the United States Government or any agency thereof. The views and opinions of authors expressed herein do not necessarily state or reflect those of the United States Government or any agency thereof. 
Energy and Transportation Science Division

\title{
SMART INFRARED INSPECTION SYSTEM FIELD OPERATIONAL TEST
}

\author{
Adam Siekmann \\ Gary Capps \\ Oscar Franzese \\ Mary Beth Lascurain
}

Date Published: June 2011

Prepared by

OAK RIDGE NATIONAL LABORATORY

Oak Ridge, Tennessee 37831-6283

managed by

UT-BATTELLE, LLC

for the

U.S. DEPARTMENT OF ENERGY

under contract DE-AC05-00OR22725 
[This page intentionally left blank.] 


\section{TABLE OF CONTENTS}

ABBREVIATIONS, ACRONYMS, AND SYMBOLS ............................................... viii

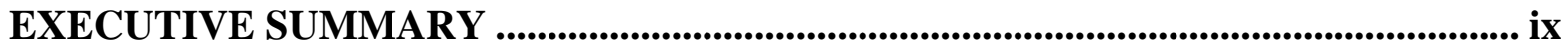

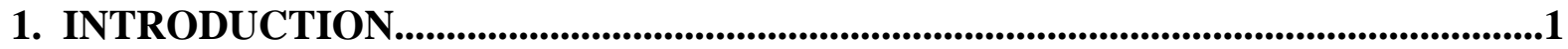

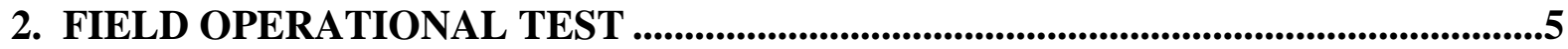

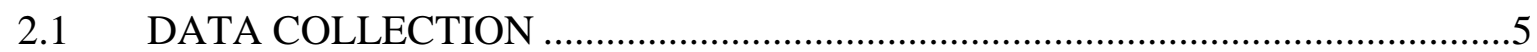

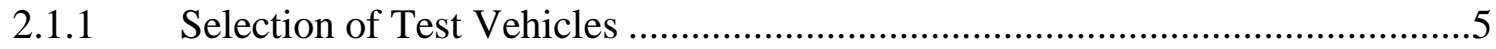

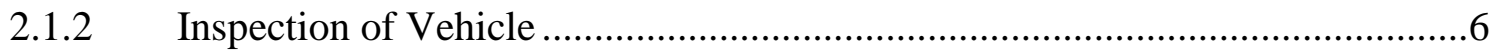

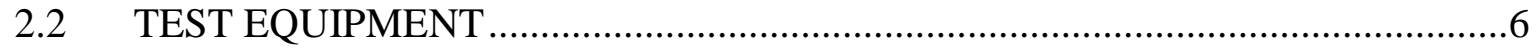

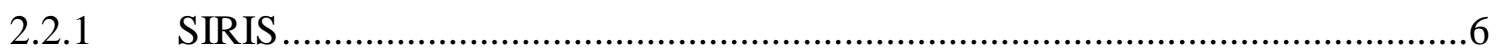

2.2.2 Performance-Based Brake Tester ...................................................................9

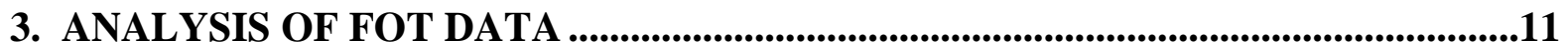

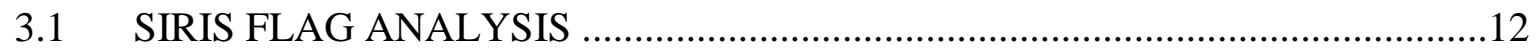

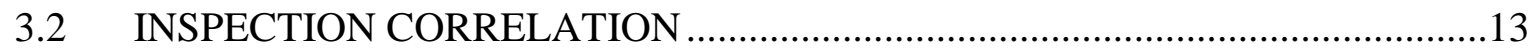

3.3 COMMON VIOLATIONS OF SIRIS FLAGGED VEHICLES ..........................15

3.3.1 Brake Violations ..................................................................................16

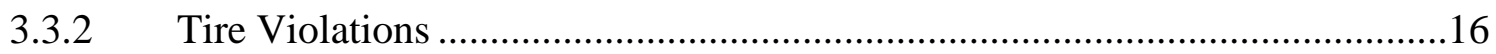

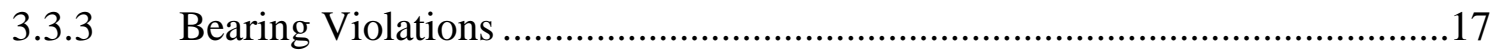

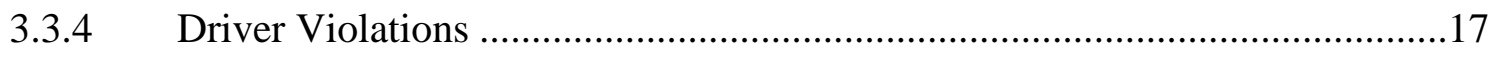

3.3.5 Miscellaneous Vehicle Violations .............................................................17

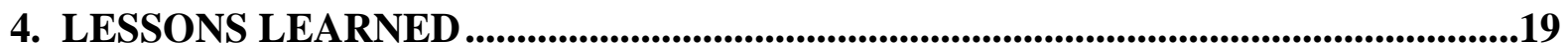

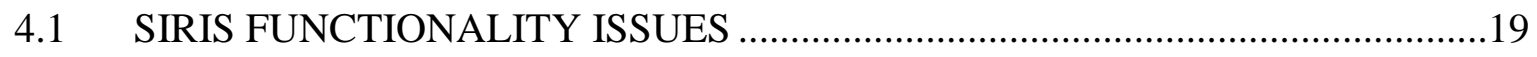

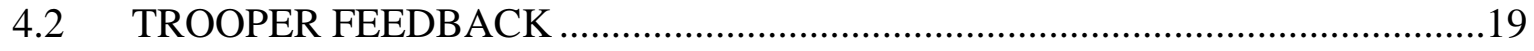

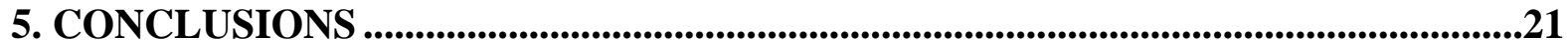

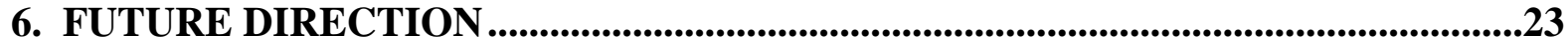

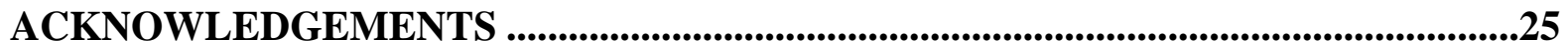




\section{LIST OF APPENDICES}

APPENDIX A: MAINLINE BRAKE ASSESSMENT CORRELATION LOG SHEET .......27

APPENDIX B: VIOLATIONS ASSOCIATED WITH SIRIS ........................................29

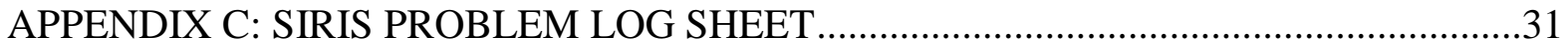

APPENDIX D: SIRIS FIELD OPERATIONAL TEST QUESTIONNAIRE ........................33

APPENDIX E: TENNESSEE HIGHWAY PATROL QUESTIONNAIRE ANSWERS .......35

APPENDIX F: SIRIS OPERATIONS MANUAL …......................................................37 


\section{LIST OF FIGURES}

Figure 1. Driver's side components of the SIRIS system. ...............................................

Figure 2. Passenger side components of the SIRIS system. .............................................

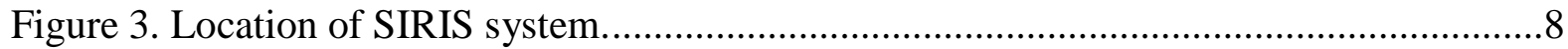

Figure 4. Performance based brake tester, located at Greene County Inspection Station. ........9

Figure 5. Wheel-end with ROI problems........................................................................11

Figure 6. Wheel-end with no ROI detected. ................................................................11

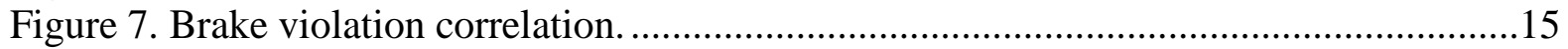

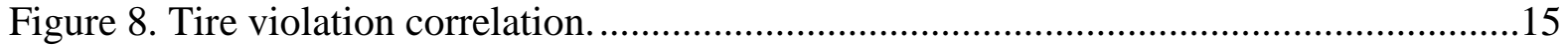

\section{LIST OF TABLES}

Table 1. 2009 Summary of SIRIS Test Results ....................................................................2

Table 2. 2009 Detailed Summary of SIRIS Flags..............................................................

Table 3. Percentage of ROI Problems Per Wheel End …................................................12

Table 4. Summary of SIRIS FOT Results ........................................................................12

Table 5. Detailed Summary of SIRIS Flags.......................................................................13

Table 6. Summary of Results Per Number of SIRIS Flags................................................13

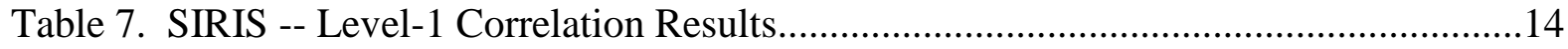

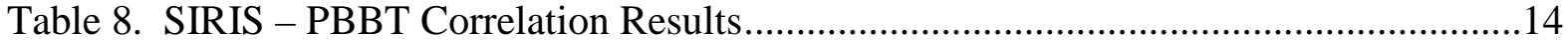

Table 9. Brake Violations of Vehicles Flagged by SIRIS ..............................................16

Table 10. Tire Violations of Vehicles Flagged by SIRIS ..................................................16

Table 11. Bearing Violations of Vehicles Flagged by SIRIS ...........................................17

Table 12. Driver Violations of Vehicles Flagged by SIRIS ............................................17

Table 13. Miscellaneous Violations of Vehicles Flagged by SIRIS ....................................18 


\section{ABBREVIATIONS, ACRONYMS, AND SYMBOLS}

\begin{tabular}{ll} 
CMV & commercial motor vehicle \\
CMVRTC & Commercial Motor Vehicle Roadside Technology Corridor \\
FOT & Federal Motor Carrier Safety Administration \\
GUI & field operational test \\
IEM & graphical user interface \\
IS & International Electronic Machine \\
NAS & inspection station \\
OOS & North American Standard \\
ORNL & Out of service \\
PBBT & Oak Ridge National Laboratory \\
ROI & performance-based brake tester \\
SIRIS & region of interest \\
TDOS & Smart InfraRed Inspection System \\
TDOT & Tennessee Department of Safety \\
THP & Tennessee Department of Transportation \\
\hline
\end{tabular}




\section{EXECUTIVE SUMMARY}

The Smart InfraRed Inspection System (SIRIS) is a tool designed to assist inspectors in determining which vehicles passing through SIRIS are in need of further inspection. This is accomplished by measuring thermal data from the wheel components. As a commercial motor vehicle (CMV) travels through the system, infrared cameras mounted on the roadside measure temperatures of the brakes, tires, and wheel bearings on both wheel ends of the vehicle. This thermal data is analyzed by SIRIS internally before being presented to enforcement personnel on a user-friendly interface inside the inspection station. Vehicles that are suspected to have a defect are automatically alerted to the enforcement staff.

The main goal of the SIRIS field operational test (FOT) was to collect data to evaluate the performance of the prototype system and to determine the viability of such a system for use in CMV enforcement. From March 2010 to September 2010, ORNL facilitated the SIRIS FOT at the Greene County Inspection Station (IS) in Greeneville, Tennessee. During the course of the FOT, 413 CMVs were given a North American Standard (NAS) Level-1 inspection. Of those 413 CMVs, 384 were subjected to a SIRIS screening. A total of 36 (9.38\%) of the vehicles screened by SIRIS were flagged by the system as having one or more thermal issues, with brakes issues making up 33 (91.67\%) of those. Of the 36 vehicles flagged as having thermal issues, 31 (86.11\%) were found to have a violation and 30 (83.33\%) of those vehicles were placed out-ofservice (OOS).

Overall, the enforcement personnel who have used SIRIS for screening purposes have given positive feedback on the potential of SIRIS. With improvements in detection algorithms and stability, the system will be beneficial to the CMV enforcement community and increase overall trooper productivity by accurately identifying a higher percentage of CMVs to be placed OOS with minimal error.

No future evaluation of SIRIS has been deemed necessary and specifications for a production system will soon be drafted. 
[This page intentionally left blank.] 


\section{INTRODUCTION}

In 2006, International Electronic Machines Corporation (IEM), with support from U.S. Department of Transportation, Federal Motor Carrier Safety Administration (FMCSA) and the New York State Energy Research and Development Authority, began to develop the Smart Infrared Inspection System (SIRIS) to address many limitations of current thermal prescreening programs.

SIRIS is a tool designed to assist inspectors in determining which commercial motor vehicles (CMV) passing through the SIRIS system are in need of further inspection. SIRIS collects thermal data from the wheel components and flags anomalies based on temperature differences which indicate possible vehicle deficiencies such as dragging brakes, inoperative brakes, underinflated tires, and wheel bearing failures. As a CMV enters the system, infrared cameras mounted at the roadside measure temperatures of the brakes, tires, and wheel bearings on both wheel ends of the CMV in motion. This thermal data is analyzed internally before being presented to enforcement personnel on a user-friendly interface inside the inspection station (IS). The enforcement staff is automatically alerted to CMVs that are suspected to have a defect.

During the summer of 2007, a first-generation prototype version of the system was deployed at the Greene County, Tennessee, CMV IS within the Commercial Motor Vehicle Roadside Technology Corridor (CMVRTC) for proof-of-concept testing. The SIRIS prototype consisted of roadway components that collected thermal data of brakes, tires, and bearings to be collected by infrared cameras while the vehicle was in motion. The ability to screen vehicles in motion allowed for seamless integration into the IS without interfering with normal operation. The prototype also automatically alerted enforcement personnel of any potential defect on a user interface located inside the IS. For a full description for the SIRIS components and system operation, see Appendix F.

Out of that effort, IEM made adjustments to the system configuration. In 2008, IEM made additional modifications to the overall SIRIS configuration. Based on these modifications, a second generation of the SIRIS prototype was deployed for data collection and verification purposes at inspection sites in New York and New Jersey. The data obtained from these sites was analyzed by the University of Michigan Transportation Research Institute with the goal of generating a set of statistically-based rules for automatic vehicle evaluation. Initial analysis resulted in a rule that, when applied to actual Level-1 data, allowed SIRIS to accurately identify nearly $65 \%$ of the vehicles with brake problems, with a very low false positive rate.

In late April 2009, IEM returned its prototype SIRIS to the Greene County site for a three-week system test and demonstration. For this demonstration, SIRIS used its intelligent imaging evaluation capability. Employing a set of empirically-derived rules from earlier work in Tennessee, New York, and New Jersey, SIRIS automatically evaluated each CMV as it passed by and, via a combined audio and visual alert, notified the inspectors at the CMV IS of possible issues with scanned vehicles. Inspectors were taught how to use the SIRIS software to access more detailed thermal information to decide which vehicles required inspection. Of the approximately 2,500 vehicles that were evaluated by SIRIS during the April testing, 232 (about 
9\%) were flagged as having possible issues with brakes, tires, or bearings. While not conducting a controlled test program during the three-week period, inspectors at the weigh station did conduct 29 Level-1 inspections on vehicles flagged by SIRIS. Of those vehicles inspected, 22 (76\%) had relevant violations found and 17 (59\%) were placed out-of-service (OOS), mostly for brake related issues. The three-week program culminated in a day-long demonstration on May 7 to a number of key individuals from Tennessee Departments of Safety (TDOS) and Transportation (TDOT) ), the Kentucky Transportation Center of the University of Kentucky, FMCSA, and Oak Ridge National Laboratory (ORNL). During the demonstration four vehicles were flagged and inspected; three of those were placed OOS, and the fourth had a non-functional brake but was not placed OOS. During the demonstration, each of those vehicles was also tested on the Performance-Based Brake Tester (PBBT) with results consistent with those generated by SIRIS.

After the April 2009 testing, SIRIS was tested by ORNL at the Greene County IS for a 15-day period during July and August 2009. During the testing, SIRIS operated completely autonomously, evaluating vehicles as they passed through the ramp to the pit scale. The system then alerted inspectors when a thermal anomaly was encountered with a vehicle's brakes, tires, or wheel-end bearings. SIRIS evaluated a total of 4,373 CMVs during this pilot testing. A total of 359 (8.2\%) of those evaluated were flagged for one or more thermal issues, with brakes comprising the largest portion of problems. The majority of CMVs flagged by SIRIS were then given a PBBT test and an NAS Level-1 or NAS Level-2 inspection. This resulted in a total of 275 Level-1 and PBBT inspections and 30 Level-2 inspections being performed. For these 305 vehicle inspections, 193 vehicles were placed OOS for safety issues and an additional 41 inspected vehicles were found to have safety defects that were noted but did not meet OOS criteria. These results are shown in Table 1 and Table 2 below.

Table 1. 2009 Summary of SIRIS Test Results

\begin{tabular}{lc}
\hline \multicolumn{1}{c}{ Total Vehicles Scanned by SIRIS } & $\mathbf{4 , 3 7 3}$ \\
\hline Total Vehicles Flagged by SIRIS & $359(8.2 \%)$ \\
Flagged for Brakes & 328 \\
Flagged for Tires & 29 \\
Flagged for Bearings & 2 \\
Total Vehicles Subjected to Inspection & 305 \\
Total Vehicles Placed OOS for Reason Directly Related to SIRIS Flag & $193(63.3 \%)$ \\
Total Vehicles with Any Flaws Found & $234(76.7 \%)$ \\
\hline
\end{tabular}


Table 2. 2009 Detailed Summary of SIRIS Flags

\begin{tabular}{|c|c|c|c|c|}
\hline $\begin{array}{l}\text { Type of Flaw } \\
\text { Detected }\end{array}$ & Inspections & OOS & $\begin{array}{c}\text { Related Issue or } \\
\text { Violation }\end{array}$ & $\begin{array}{l}\text { Nothing } \\
\text { Found }\end{array}$ \\
\hline Brakes & 274 & $\begin{array}{c}174 \\
63.5 \%\end{array}$ & $\begin{array}{c}33 \\
12.0 \%\end{array}$ & $\begin{array}{c}67 \\
24.5 \%\end{array}$ \\
\hline Tires & 29 & $\begin{array}{c}18 \\
62.1 \%\end{array}$ & $\begin{array}{c}8 \\
27.6 \%\end{array}$ & $\begin{array}{c}3 \\
10.3 \%\end{array}$ \\
\hline Bearings & 2 & $\begin{array}{c}1 \\
50.0 \% \\
\end{array}$ & $\begin{array}{l}- \\
- \\
\end{array}$ & $\begin{array}{c}1 \\
50.0 \% \\
\end{array}$ \\
\hline Total & 305 & $\begin{array}{c}193 \\
63.3 \%\end{array}$ & $\begin{array}{c}41 \\
13.4 \%\end{array}$ & $\begin{array}{c}71 \\
23.3 \%\end{array}$ \\
\hline
\end{tabular}


[This page intentionally left blank.] 


\section{FIELD OPERATIONAL TEST}

The FOT was conducted at the Greene County IS, located on I-81 South in Greeneville, Tennessee for a period of 7 months (March 2010 through September 2010).

\subsection{DATA COLLECTION}

In order to conduct an unbiased evaluation of the SIRIS technology, a test plan was created for enforcement personnel to follow during the FOT. During February 2010, pre-FOT testing was conducted in order to familiarize inspection staff with the test plan and to confirm that the procedures in the test plan were feasible.

Enforcement personnel were asked to perform five inspections during their shift. This number was chosen to allow for thoroughness of the inspections and record keeping. It was understood that this number of inspections would not be met during all shifts due to circumstances out of the officer's control (e.g. vehicle condition, carrier OOS orders, driver arrest, system downtime due to hardware malfunction and/or weather).

All inspection data was collected in paper format at the inspection station, and electronic data from the ASPEN inspection reports, sanitized of all personally identifiable driver information (e.g. driver name, license number, date of birth), was also received from TDOS in Nashville. This data was processed using data analysis software developed by ORNL.

\subsubsection{Selection of Test Vehicles}

To provide a representative sample of all vehicles traveling on I-81 South during the test period, selection of the vehicles was done according to a strict procedure. The plan allowed for all vehicles on the mainline to be sampled (including PrePass participants), while recognizing and mitigating the risk for significant backup from the pit scale. The following outlines the procedure:

1. Turn off PrePass (set to 100\%) and divert all CMVs to the high-speed bypass lane (so that the vehicles in this lane will be representative of the mainline).

2. Wait at least one minute so the stream of vehicles in the high-speed bypass lane is representative of all vehicles on the mainline (both PrePass and non-PrePass). The pit scale lane should be empty before proceeding to step 3.

3. Divert four consecutive vehicles to the pit scale (diverting these vehicles into the path of the SIRIS system).

4. Divert remaining vehicles back to the high-speed bypass lane and turn PrePass back on (previous setting), returning all scale facilities to normal operations.

5. Select the fourth vehicle in the queue for the pit scale for inspection under this FOT, 
regardless of the type of vehicle. This vehicle must be inspected to the fullest extent possible. If the vehicle cannot be placed on the PBBT or inspection pit, conduct as thorough an inspection as possible and note the areas that could not be inspected on the $\log$ sheet.

\subsubsection{Inspection of Vehicle}

Once the vehicle was selected and driver information was checked, the enforcement personnel directed the vehicle to the inspection pit to perform a Level-1 inspection. To keep the evaluation process unbiased, the enforcement personnel performing the Level-1 inspection were not permitted to look at any SIRIS data prior to conducting the inspection. After completing a thorough inspection, the vehicle was directed to pull onto the PBBT. A PBBT test was performed last so that the inspector would not be knowledgeable of any possible brake defects that would be identified by the PBBT.

After these inspections were complete, the inspector recorded all inspection numbers, times and general vehicle information on the log sheet provided (Appendix A). Normal enforcement protocol was followed regarding any vehicle and/or driver found to have OOS defects.

\subsection{TEST EQUIPMENT}

\subsubsection{SIRIS}

SIRIS as tested included the following components:

- Two thermal infrared cameras, one on either side of the lane;

- One visible camera;

- One vehicle presence detection sensor;

- Wheel triggers;

- Roadside electronics for system control and power management;

- Cross lane cabling for remote camera system;

- Fiber cable from roadside to in-scale-house computer;

- Computer system and monitor;

- SIRIS software to evaluate vehicles and to make notification when vehicles with the following conditions were detected:

- Unusually cool brakes,

- Overheated brakes,

- Overheated tires, and

- Overheated wheel bearings.

The roadside SIRIS components are shown in Figure 1 and Figure 2. 


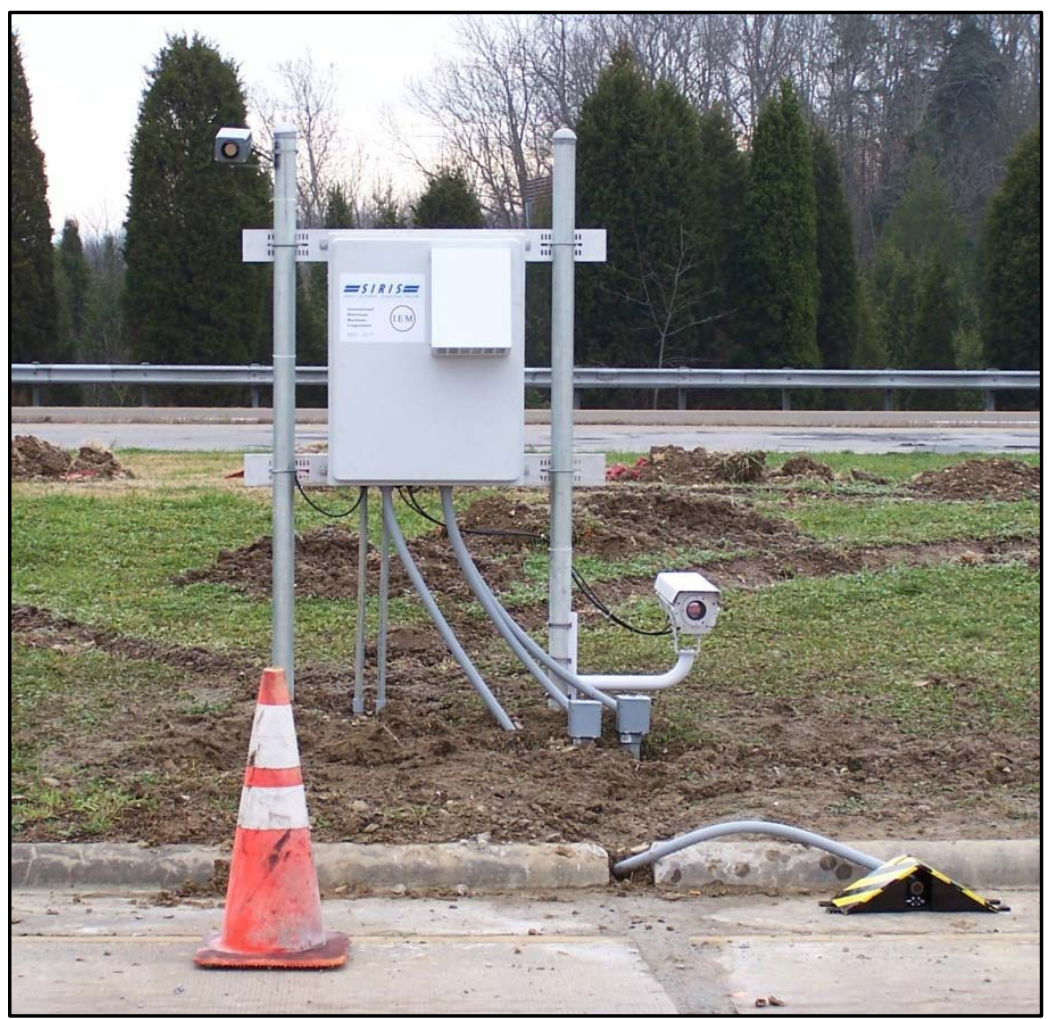

Figure 1. Driver's side components of the SIRIS system.

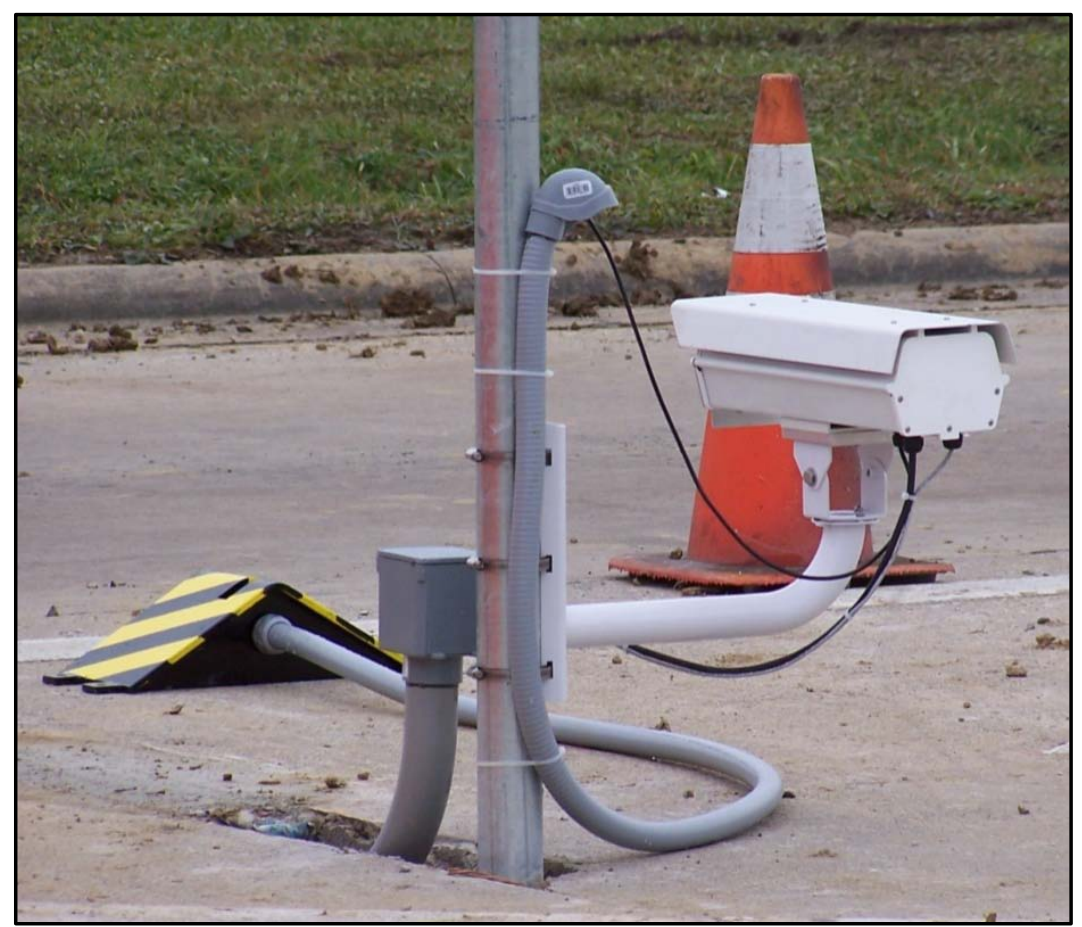

Figure 2. Passenger side components of the SIRIS system. 
The SIRIS system was located on the entrance ramp to the pit scale as shown in Figure 3. This location is approximately 200 feet from the IS building, allowing for wide-load vehicles exiting from the parking area to turn back onto the pit scale without the danger of damaging the SIRIS equipment.

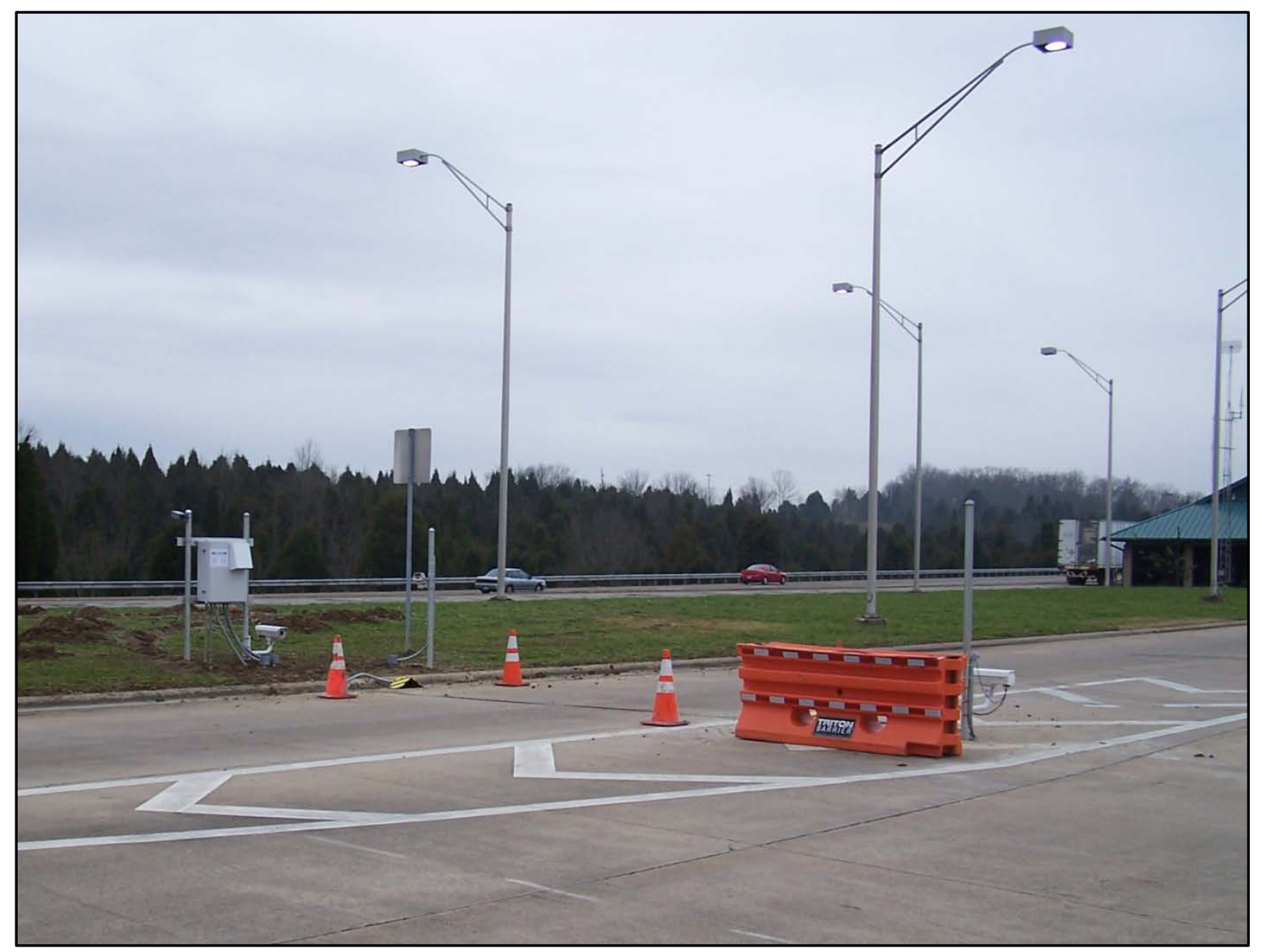

Figure 3. Location of SIRIS system. 


\subsubsection{Performance-Based Brake Tester}

The PBBTs are devices that can evaluate the current brake efficiency of a vehicle by measuring brake forces developed as the vehicle engages in a braking event while stationed on the device. Since the Greene County IS has an in-ground roller dynamometer PBBT (see Figure 4), testing was also conducted to determine if any correlation existed between SIRIS flags and a PBBT inspection.

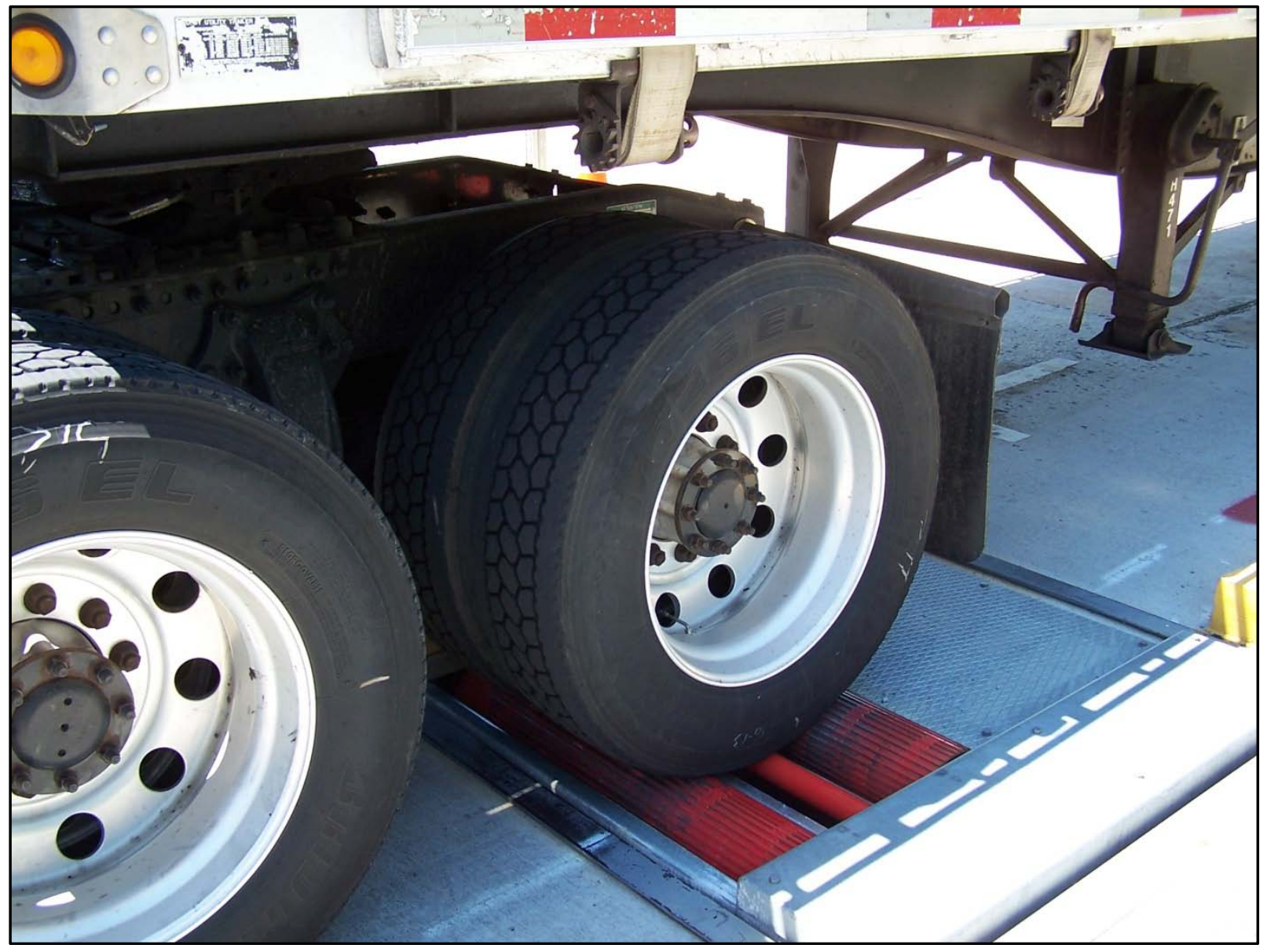

Figure 4. Performance based brake tester, located at Greene County Inspection Station. 
[This page intentionally left blank.] 


\section{ANALYSIS OF FOT DATA}

The main goal of the SIRIS FOT was to collect data to evaluate the performance of this prototype system and to determine the viability of such a system for use in CMV enforcement. Using a typical NAS Level-1 inspection as the "ground truth," the SIRIS data collected was evaluated for accuracy in predicting whether a vehicle would have a potential violation or be placed OOS. The violations that were considered to be SIRIS-related or "detectable" by SIRIS are listed in Appendix B.

The reliability of SIRIS is related to the quality of the image and individual temperature regions (i.e. tire, brake, and bearing). These temperature regions are referred to as regions of interest (ROIs). If the ROI is off-center (see Figure 5) or not detected at all (see Figure 6), the temperatures from those regions are not usable; therefore, wheel-ends with ROI problems were not included in the analysis.

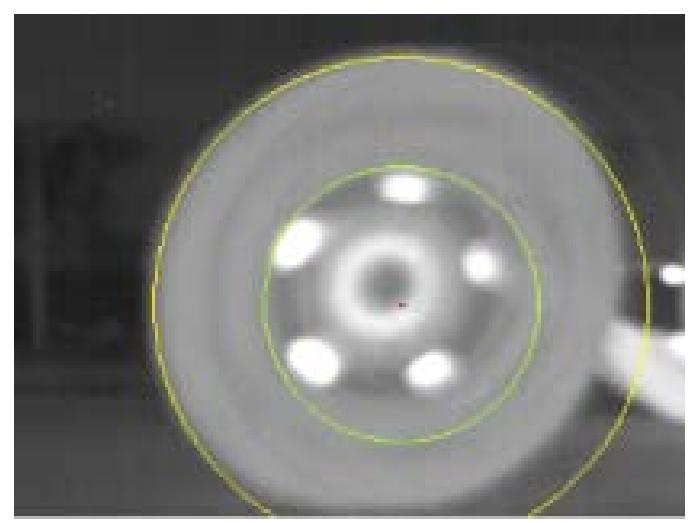

Figure 5. Wheel-end with ROI problems.

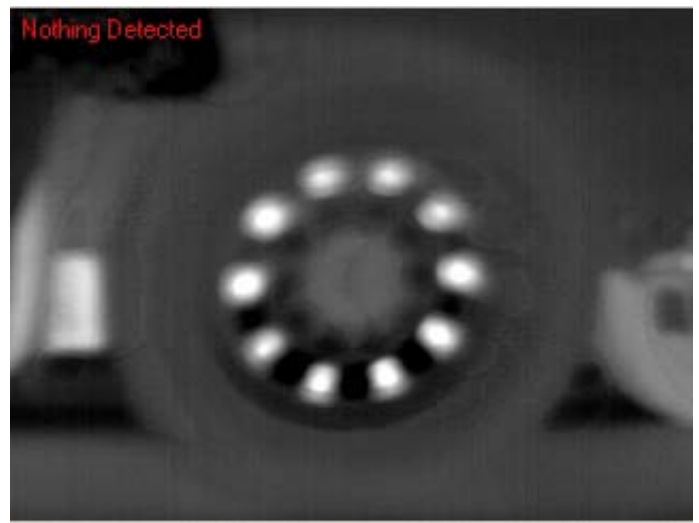

Figure 6. Wheel-end with no ROI detected.

Typically, ROI problems are caused by speeding vehicles, obstructed camera views, and hardware malfunctions. Table 3 shows the percentage of all wheel ends that had a ROI problem associated with them. 
Table 3. Percentage of ROI Problems Per Wheel End

\begin{tabular}{cc}
\hline Axle & Percent of ROI Problem \\
\hline Axle 1 L & $3.63 \%$ \\
Axle 2 L & $4.12 \%$ \\
Axle 3 L & $2.48 \%$ \\
Axle 4 L & $2.99 \%$ \\
Axle 5 L & $9.11 \%$ \\
\hline Axle 1 R & $9.93 \%$ \\
Axle 2 R & $5.81 \%$ \\
Axle 3 R & $3.22 \%$ \\
Axle 4 R & $4.73 \%$ \\
Axle 5 R & $10.89 \%$ \\
\hline
\end{tabular}

\subsection{SIRIS FLAG ANALYSIS}

During the test period, 413 vehicles were randomly selected from the mainline and 384 were scanned by SIRIS. The 29 vehicles that were not scanned by SIRIS because of system malfunction or downtime were still given a Level-1 inspection and PBBT. As shown in Table 4, 36 of the vehicles that were selected were flagged by SIRIS as possibly having a brake or tire violation (in no case did SIRIS flag for both brake and tire). All 36 of those vehicles were subjected to a Level-1 inspection resulting in 30 (83.3\%) of those vehicles being placed OOS for a related violation, and 31 (86.11\%) of the total vehicles having a flaw of some type relative to brakes, tires, or wheel bearings.

Table 4. Summary of SIRIS FOT Results

\begin{tabular}{lc}
\hline \multicolumn{1}{c}{ Total Vehicles Scanned by SIRIS } & $\mathbf{3 8 4}$ \\
\hline Total Vehicles Flagged by SIRIS & $36(9.38 \%)$ \\
Flagged for Brakes & 33 \\
Flagged for Tires & 3 \\
Flagged for Bearings & 0 \\
Total Vehicles Subjected to Inspection & 36 \\
Total Vehicles Placed OOS for Reason Directly Related to SIRIS Flag & $30(83.33 \%)$ \\
Total Vehicles with Any Flaws Found & $31(86.11 \%)$ \\
\hline
\end{tabular}

Table 5 shows a more detailed breakdown of the SIRIS flags. The majority of the flags was brake-related and had a false-positive rate of $15.2 \%$ and an $84.8 \%$ success rate in identifying a related violation on the vehicle. When a tire was flagged by SIRIS as having a potential violation, the resulting Level-1 inspection placed the vehicle OOS $100 \%$ of the time. In this particular evaluation the sample size was relatively small compared to the 2009 testing and definite conclusions about tire flags cannot be made, but from previous testing it can be inferred that the success rate on tire flags would be approximately the same, if not better than brake flags. Overall, SIRIS had an $86.11 \%$ positive flag rate. 
Table 5. Detailed Summary of SIRIS Flags

\begin{tabular}{lcccc}
\hline $\begin{array}{c}\text { Type of } \\
\text { Flaw } \\
\text { Detected }\end{array}$ & $\begin{array}{c}\text { Number of } \\
\text { Inspections }\end{array}$ & OOS & $\begin{array}{c}\text { Related Issue } \\
\text { or Violation }\end{array}$ & $\begin{array}{c}\text { Nothing } \\
\text { Found }\end{array}$ \\
\hline Brakes & 33 & 27 & 1 & 5 \\
& 3 & $81.8 \%$ & $3.0 \%$ & $15.2 \%$ \\
Tires & 0 & 3 & - & - \\
Bearings & $100 \%$ & - & - \\
\multicolumn{1}{c}{ Total } & $\mathbf{3 6}$ & $\mathbf{3 0}$ & $\mathbf{1}$ & $\mathbf{5}$ \\
\hline
\end{tabular}

When being used by enforcement personnel in the field, it is helpful to know that a vehicle flagged by SIRIS would be very likely to have an associated violation; this allows an officer to focus their time on a vehicle with brake violations. Brake problems are the most common vehicle-associated factor of large truck crashes, approximately $29 \%{ }^{1}$, thus focusing more time on brake violations would likely have an effect on the number of CMVs involved in accidents. Table 6 shows the OOS rate and violation rate of test vehicles based on the amount of SIRIS flags that occurred on the inspected vehicle. Vehicles with one or two flags were placed OOS 83.3\% of the time. When used in the field, a vehicle that is flagged by SIRIS is very likely to be placed OOS if inspected by enforcement personnel.

Table 6. Summary of Results Per Number of SIRIS Flags

\begin{tabular}{cccccc}
\hline $\begin{array}{c}\text { No. of } \\
\text { Flags }\end{array}$ & $\begin{array}{c}\text { Number of } \\
\text { Inspections }\end{array}$ & OOS Rate & $\begin{array}{c}\text { Mean Brake } \\
\text { Violation } \\
\text { Rate }\end{array}$ & $\begin{array}{c}\text { Mean Tire } \\
\text { Violation } \\
\text { Rate }\end{array}$ & $\begin{array}{c}\text { Mean } \\
\text { Bearing } \\
\text { Violation } \\
\text { Rate }\end{array}$ \\
\hline 1 & 16 & $81.25 \%$ & 2.7500 & 1.0625 & 0.0000 \\
2 & 14 & $85.71 \%$ & 3.0000 & 0.4286 & 0.0000 \\
3 & 3 & $100.00 \%$ & 7.6667 & 1.3333 & 0.6667 \\
4 & 2 & $50.00 \%$ & 2.0000 & 0.0000 & 0.0000 \\
$5+$ & 1 & $100.00 \%$ & 4.0000 & 4.0000 & 0.0000 \\
\hline
\end{tabular}

\subsection{INSPECTION CORRELATION}

Correlation data shown in Table 7 and Table 8 only includes brake-related results. Tire and bearing data was not statistically significant with only 3 total flags and is not included in the tables shown below. The findings below show that if SIRIS were to be used for anything other than a screening tool, it would not be able to reliably place vehicles OOS without a PBBT or Level-1 Inspection.

1. U.S. Department of Transportation Federal Motor Carrier Safety Administration, Report to Congress on the Large Truck Crash Causation Study. March 2006. 
Table 7. SIRIS -- Level-1 Correlation Results

\begin{tabular}{lccc}
\hline \multicolumn{1}{c}{ SIRIS Action } & Pass, no brake defects & $\begin{array}{c}\text { Pass, but defects } \\
\text { detected }\end{array}$ & Fail \\
\hline \multirow{2}{*}{ Flagged } & $1.30 \%$ & $0.26 \%$ & $7.03 \%$ \\
Not Flagged & 5 & 1 & 27 \\
& $30.73 \%$ & $4.17 \%$ & $56.51 \%$ \\
\hline
\end{tabular}

Table 8. SIRIS - PBBT Correlation Results

\begin{tabular}{lcc}
\hline \multicolumn{1}{c}{ SIRIS Action } & Vehicle Pass & Vehicle Fail \\
\hline \multirow{2}{*}{ Flagged } & $5.25 \%$ & $3.31 \%$ \\
& 19 & 12 \\
Not Flagged & $67.13 \%$ & $24.31 \%$ \\
\hline
\end{tabular}

It is interesting to note that over $50 \%$ of the vehicles which were not flagged by SIRIS were still put OOS after a Level-1 inspection and almost 25\% were placed OOS from a PBBT inspection (score less than 43.5). The number of vehicles shown in Table 8 reflects that not all vehicles scanned by SIRIS were tested on the PBBT due to system downtime (only 362 of the 384 vehicles were successfully tested on the PBBT).

Figure 7 and Figure 8 below show the relationship of violation occurrences per vehicle for SIRIS-flagged vehicles and all 413 vehicles that were inspected, including vehicles flagged by SIRIS as having potential violations. As seen in both figures, SIRIS did an excellent job of flagging vehicles with defects. In general, the percentage of vehicles that had specific violations is greater for SIRIS flagged vehicles than vehicles that were not flagged by SIRIS. The amount of tire violations was not significant, however, it is likely that the same relationship would be observed if more vehicles were flagged and inspected. 


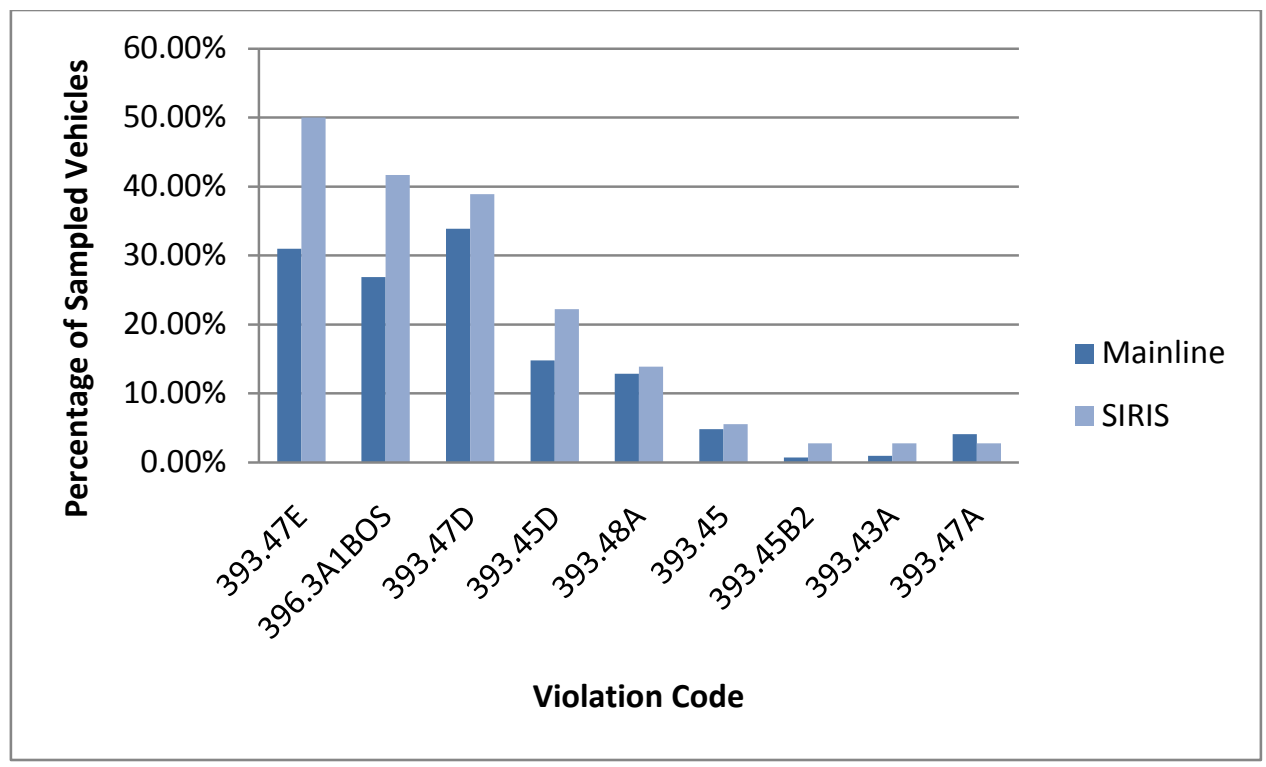

Figure 7. Brake violation correlation.

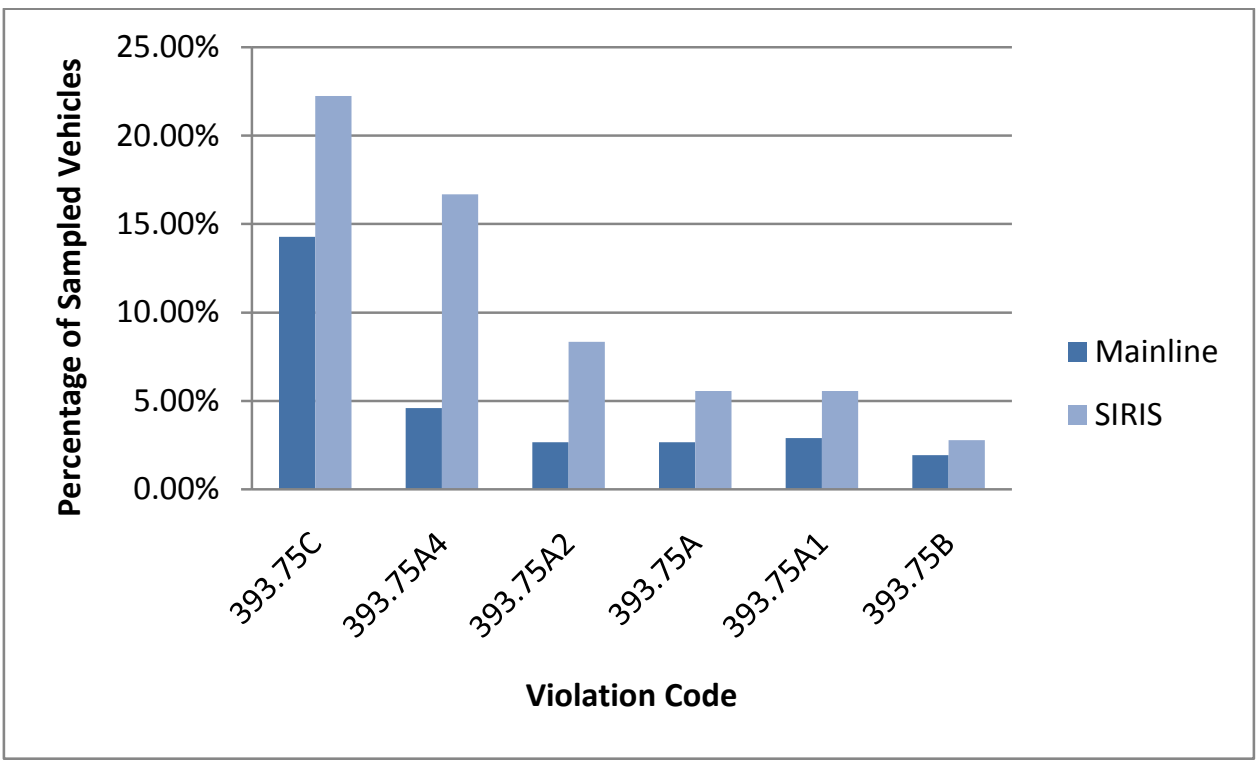

Figure 8. Tire violation correlation.

\subsection{COMMON VIOLATIONS OF SIRIS FLAGGED VEHICLES}

Vehicles that were flagged by SIRIS as having a possible violation typically had similar violations found during the Level-1 inspection. Since SIRIS uses ambient temperature and ROI temperatures to determine whether a wheel-end needs to be inspected, a detected brake flag would not necessarily mean a brake violation, but could be a sign of another possible vehicle defect that prevents the brake from performing optimally (e.g., flat tire shifted weight causing brake to exert more force to stop). The violations listed in the tables in the next subsections are shown in order of decreasing frequency in the inspected vehicles that were flagged by SIRIS. 


\subsubsection{Brake Violations}

Table 9 shows the most common brake violations of all the SIRIS vehicles that were flagged. It is clear that the majority of the brake violations found were due to insufficient brake linings and brakes being out of adjustment.

Table 9. Brake Violations of Vehicles Flagged by SIRIS

\begin{tabular}{lccl}
\hline $\begin{array}{c}\text { Violation } \\
\text { Code }\end{array}$ & $\begin{array}{c}\text { Number of } \\
\text { Vehicles } \\
\text { with } \\
\text { Violation }\end{array}$ & $\begin{array}{c}\text { Number of } \\
\text { Wheel Ends } \\
\text { with } \\
\text { Violation }\end{array}$ & \multicolumn{1}{c}{ Description of Violation } \\
\hline 393.47E & 18 & 50 & Clamp- or roto-type brake out of adjustment \\
396.3A1BOS & 15 & 15 & Brakes did not meet 20\% criteria \\
393.47D & 14 & 31 & Insufficient brake linings \\
393.45D & 8 & 8 & Brake connections with leaks or constrictions \\
393.48A & 5 & 7 & Inoperative or defective brakes \\
393.45 & 2 & 2 & Brake tubing and hose adequacy; emergency \\
& 1 & 1 & Brake hose or tubing chafing and/or kinking \\
393.45B2 & 1 & 1 & No or improper tractor protection valve \\
393.43A & 1 & 2 & Inadequate brakes for safe stopping \\
393.47A & & & \\
\hline
\end{tabular}

\subsubsection{Tire Violations}

Of the vehicles flagged by SIRIS, very few tire violations (Table 10) were found as compared to brake violations.

Table 10. Tire Violations of Vehicles Flagged by SIRIS

\begin{tabular}{lccl}
\hline $\begin{array}{c}\text { Violation } \\
\text { Code }\end{array}$ & $\begin{array}{c}\text { Number of } \\
\text { Vehicles } \\
\text { with } \\
\text { Violation }\end{array}$ & $\begin{array}{c}\text { Number of } \\
\text { Wheel Ends } \\
\text { with Violation }\end{array}$ & \multicolumn{1}{c}{ Description of Violation } \\
\hline 393.75C & 8 & 15 & Tire-other tread depth less than 2/32 of inch \\
393.75A4 & 6 & 8 & Tire-cut exposing ply and/or belt material \\
393.75A2 & 3 & 3 & Tire-tread and/or sidewall separation \\
393.75A & 2 & 2 & Flat tire or fabric exposed \\
393.75A1 & 2 & 2 & Tire-ply or belt material exposed \\
393.75B & 1 & 1 & Tire-front tread depth less than 4/32 of inch \\
\hline
\end{tabular}




\subsubsection{Bearing Violations}

Shown in Table 11, there was only 1 vehicle which had a bearing violation and no SIRIS bearing violations. Based on the number of vehicles flagged, this is not a significant finding.

Table 11. Bearing Violations of Vehicles Flagged by SIRIS

\begin{tabular}{cccc}
\hline $\begin{array}{c}\text { Violation } \\
\text { Code }\end{array}$ & $\begin{array}{c}\text { Number of } \\
\text { Vehicles } \\
\text { with } \\
\text { Violation }\end{array}$ & $\begin{array}{c}\text { Number } \\
\text { Wheel Ends } \\
\text { with } \\
\text { Violation }\end{array}$ & Description of Violation \\
\hline 393.209D & 1 & 2 & $\begin{array}{c}\text { Steering system components worn, welded, or } \\
\text { missing }\end{array}$ \\
\hline
\end{tabular}

\subsubsection{Driver Violations}

From the driver violations shown below in Table 12 there was no correlation between vehicles with violations and drivers violations of the SIRIS flagged vehicles.

Table 12. Driver Violations of Vehicles Flagged by SIRIS

\begin{tabular}{lcl}
\hline $\begin{array}{c}\text { Violation } \\
\text { Code }\end{array}$ & $\begin{array}{c}\text { Number of } \\
\text { Drivers with } \\
\text { Violation }\end{array}$ & \multicolumn{1}{c}{ Description of Violation } \\
\hline 391.11B4 & 4 & Using a physically unqualified driver \\
392.16 & 4 & $\begin{array}{l}\text { Failing to use seat belt while operating CMV } \\
\text { 395.8E }\end{array}$ \\
392.5A & 1 & False report of drivers record of duty status \\
395.8 & 1 & Driver consuming an intoxicating beverage within 4 hours \\
392.2 & 1 & Lecord of Duty Status violation (general/form and manner) \\
\hline 392.60A & 1 & Unauthorized passenger on board CMV \\
395.3A2/R & 1 & 14 hour rule violation (Property) \\
395.8A & 1 & No drivers record of duty status \\
392.2W & 1 & Size and weight \\
395.8F1 & 1 & Drivers record of duty status not current \\
395.3A1/R & 1 & 11 hour rule violation (Property) \\
391.45B & 1 & Expired medical examiner certificate \\
\hline
\end{tabular}

\subsubsection{Miscellaneous Vehicle Violations}

Similar to the driver violations, the miscellaneous violations shown in Table 13 have no correlation with the SIRIS flagged vehicles. 
Table 13. Miscellaneous Violations of Vehicles Flagged by SIRIS

\begin{tabular}{|c|c|c|c|}
\hline $\begin{array}{c}\text { Violation } \\
\text { Code }\end{array}$ & $\begin{array}{c}\text { Number of } \\
\text { Vehicles } \\
\text { with } \\
\text { Violation }\end{array}$ & $\begin{array}{c}\text { Total } \\
\text { Occurrences }\end{array}$ & Description of Violation \\
\hline 393.9TS & 5 & 8 & Inoperative turn signal \\
\hline 396.7 & 5 & 6 & Unsafe operations forbidden \\
\hline 393.53B & 3 & 3 & $\begin{array}{l}\text { CMV manufactured after 10/19/94 has an } \\
\text { automatic airbrake adjustment system that fails to } \\
\text { compensate for wear }\end{array}$ \\
\hline 396.17C & 2 & 2 & Operating a CMV without periodic inspection \\
\hline 392.9A & 1 & 1 & Failing to secure load \\
\hline $393.25 \mathrm{~F}$ & 1 & 1 & Stop lamp violations \\
\hline $393.207 \mathrm{~A}$ & 1 & 1 & Axle positioning parts defective/missing \\
\hline 393.95A & 1 & 1 & No/discharged/unsecured fire extinguisher \\
\hline $393.201 \mathrm{~A}$ & 1 & 1 & Frame cracked / loose / sagging / broken \\
\hline 393.9 & 1 & 1 & Inoperable required lamp \\
\hline 396.5B & 1 & 1 & Oil and/or grease leak \\
\hline 393.76 & 1 & 1 & Sleeper berth requirement violations \\
\hline 392.2RG & 1 & 1 & State vehicle registration or license plate violation \\
\hline 392.2FT & 1 & 1 & State or International Fuel Tax (IFTA) violation \\
\hline $393.60 \mathrm{C}$ & 1 & 1 & Damaged or discolored windshield \\
\hline 393.104B & 1 & 1 & Damaged securement system/tiedowns \\
\hline 392.2IRP & 1 & 1 & IRP apportioned tag or registration violation. \\
\hline $393.9 \mathrm{H}$ & 1 & 1 & Inoperable head lamps \\
\hline 392.2WC & 1 & 1 & Wheel (mud) flaps missing or defective. \\
\hline $393.100 \mathrm{~A}$ & 1 & 1 & No or improper load securement \\
\hline 392.60A & 1 & 1 & Unauthorized passenger on board CMV \\
\hline 393.9T & 1 & 1 & Inoperable tail lamp \\
\hline 392.2 & 1 & 1 & Local laws (general) \\
\hline 393.7 & 1 & 1 & Fifth wheel \\
\hline $392.2 \mathrm{~W}$ & 1 & 1 & Size and weight \\
\hline 393.43 & 1 & 1 & No or improper breakaway or emergency braking \\
\hline $385.325 \mathrm{C}$ & 1 & 1 & $\begin{array}{l}\text { Operating in interstate commerce on or after the } \\
\text { Operational Out of Service order date }\end{array}$ \\
\hline 392.2DIM & 1 & 1 & Dimension violation \\
\hline
\end{tabular}




\section{LESSONS LEARNED}

\subsection{SIRIS FUNCTIONALITY ISSUES}

During the course of the FOT, there were 12 recorded instances that SIRIS became inoperable or performed in a manner that made it unusable by IS personnel. ORNL staff and inspection personnel were asked to keep track of any problems with SIRIS by logging them onto the "SIRIS Problem Log Sheet" (Appendix C). Not all problems were logged due to the busy nature of the IS. However, the majority of the problems recorded was similar in nature and easily corrected with a system reboot. There was a period of time in which SIRIS was nonfunctioning due to a hardware malfunction; no testing was performed during this time. The situation was resolved in a timely manner by IEM and did negatively affect the FOT data collection period.

The major problem with SIRIS throughout the FOT was the effect of weather on the image quality and functionality of the system. Whenever there was cold weather, the incidence of false positive flags increased dramatically based on anecdotal evidence from the troopers and ORNL staff, especially related to tires. When there was heavy precipitation present, the image quality was reduced, which caused fewer flagged vehicles to be observed and the system would randomly take pictures even if no vehicle was present. It should be noted that enforcement personnel typically do not inspect vehicles in harsh weather, thus, weather anomalies did not negatively affect the results during the FOT. The troopers also noted on the log sheets downtime of the system due to power surges during storms or unexpected malfunctions during normal use.

Another issue with SIRIS was related to the software and/or hardware inside the IS. Occasionally the SIRIS graphical user interface (GUI) would lock up and not inspect vehicles until the power to the cameras was cycled or the computer was rebooted. This usually occurred on a regular basis during the FOT. It was noted that this phenomenon typically occurred after a vehicle passed too quickly through SIRIS.

\subsection{TROOPER FEEDBACK}

At the end of the evaluation, enforcement personnel familiar with SIRIS were asked questions (Appendix D) regarding the functionality of SIRIS, and how they see SIRIS being used in the future. ORNL received five completed questionnaires (responses to questionnaires in Appendix E).

In general, the feedback received was positive. SIRIS is believed to have great potential in the enforcement community relative to increased productivity when used as a screening tool. However, all of the troopers agreed that in its current condition, SIRIS was not ready for national deployment with the main reasons being stability and accuracy in flagging vehicles with potential defects. Many of the troopers were not happy with the level of downtime for SIRIS and the number of times that the cameras had to be reset in order for vehicles to be detected.

Many troopers would like the detection rate to be higher (around 10\% in current condition), and when a vehicle is flagged, they want to absolutely be certain that it will have a violation or be 
placed OOS. Also, due to the amount of false-alarms, troopers mentioned that in some cases the SIRIS alarms were not as helpful as the actual temperatures on the SIRIS GUI in determining if a vehicle needed to be inspected. In these situations, the troopers used their experience with SIRIS to determine whether or not a vehicle should be pulled in for inspection following an alert. While it would be impossible to flag every single vehicle with a possible defect, the likelihood of a vehicle having a defect if flagged cannot be overlooked. Since not all vehicles can be inspected due to limited resources, using SIRIS as a screening tool to determine if a vehicle should be inspected is a great improvement over the traditional method of choosing vehicles. 


\section{CONCLUSIONS}

The SIRIS device developed and presented to ORNL for testing for this FOT proved to be a viable screening tool for the detection of vehicles with brake defects when one excludes the stability and operational issues encountered during the data collection period. This was borne out by the data analysis (81.8\% of the vehicles flagged by SIRIS were placed OOS for brakes) and by testimonies from the THP staff who used the device on a day-to-day basis. Additionally, for the small sample of tire data, it appears that SIRIS may be an effective screening tool for dangerously overheated tires due to pressure or loading issues.

While the vehicle defect and OOS statistics for the vehicles flagged by SIRIS are impressive, the automated nature of the SIRIS system bridges the gap between being just another timeconsuming enforcement tool and viable screening system for use in low-speed applications. The use of SIRIS in high-speed applications would not be desirable because in order to assess brake functionality thermally, the vehicle's brakes would need to be applied before the thermal scan is completed. Ideally, the system would be placed directly in front of a pit scale to take full benefit of the braking event. However, at the Greene County IS this was not physically possible because of lane width.

The overall value to enforcement of the current SIRIS system is mitigated, to a large degree, by the documented instability and operational issues believed to be caused by power fluctuation and inclement weather, and SIRIS's sensitivity to vehicles traveling at speeds greater than the thermal system can accurately detect. The latter issue could be corrected by the deploying site with proper machine placement and speed control signage.

From a qualitative standpoint, the SIRIS device, if deployed, could focus the limited resources of commercial vehicle inspection agencies to inspect vehicles with a high probability of having a brake or tire defect. From a quantitative standpoint, the inability of the current SIRIS device to remain operational within the ramp-side environment precludes its value to enforcement. Work must be done to overcome the stability and operational issues with the overall system for SIRIS to become a viable mainstream tool. These stability and operational issues should not overshadow the fact that the current optical system and decision-making algorithm have produced results that could clearly have a positive effect on the OOS rates of commercial vehicles and the related accident, personal injury, and death rates. 
[This page intentionally left blank.] 


\section{FUTURE DIRECTION}

Based on the data collected over the past two years at the Greene County IS and the findings of this report, ORNL believes that no additional evaluation is required of the SIRIS system algorithm at this time. As a screening tool, a user can be relatively assured that a vehicle flagged by SIRIS will have a verifiable defect with minimal false positives expected. It is understood that certain aspects of the system need improvement. It is desirous that the overall system be more stable during weather events and power fluctuations.

The next step for creating a nationally-deployable infrared screening tool similar to SIRIS is to create functional and performance specifications that can be used by a state interested in deploying this type of equipment. The specification should be based on the performance and capabilities of SIRIS and should require a more rugged system than the current prototype.

It is suggested that all first-order testing, validation and certification of future infrared inspection systems be done at the Greene County IS to allow the testing and performance measurement of these systems to be done in the same operational and vehicle stream environment (I-81 southbound) as the SIRIS proof-of-concept, pilot test, and FOT. 
[This page intentionally left blank.] 


\section{ACKNOWLEDGEMENTS}

The CMVRTC team would like to thank the Tennessee Highway Patrol and the staff of the Greene County Commercial Motor Vehicle Inspection Station for their support of this research over the past 3 years. Without their effort to collect the required data, this research would not have been possible.

The CMVRTC team would like to thank IEM for providing the SIRIS system, installing the system, and supporting the FOT throughout the 3-week timeframe.

The CMVRTC team would like to thank TDOT for their preparation of the Greene County site for installation of the SIRIS system including, but not limited to, installing camera mounting poles, installing cable conduit across ramp, running fiber optical cable, and running power to the SIRIS control cabinet.

The CMVRTC team would like to thank FMCSA for providing programmatic oversight and funding for the execution of the test plan during the FOT.

The CMVRTC team also acknowledges each ORNL staff member for their participation in the testing of the FOT. This included drafting the test plan, conducting the testing, coordinating with TDOS for staff support, analyzing the collected data, and writing this report. 
[This page intentionally left blank.] 


\section{APPENDIX A: MAINLINE BRAKE ASSESSMENT CORRELATION LOG SHEET}

In order to make this test unbiased, please make sure that the SIRIS monitor and sound are turned off, and the results are not used or collected until after the Level-1 and PBBT. Please also take measures to ensure proper times for tests are recorded. The target number of inspections for an eight-hour shift is five (5) (or three (3) for a four-hour shift). It is understood that the target number of inspections may not be reached due to complications arising from a given inspection. If the target number of inspections cannot be reached in a given shift, please note the extenuating circumstance(s). Note: Care and thoroughness of inspection and supporting paperwork are far more important than the number of inspections performed (for the purposes of this research and the overtime grant).

This log sheet is to be used for randomly-selected vehicles ONLY.

\begin{tabular}{l} 
Tractor Description \\
Color: \\
Ownership/Operation \\
\\
$\square$ Independent owner ${ }^{\text {Company-owned }}$ \\
\hline Leased \\
Trailer Description \\
Color: \\
Ownership/Operation \\
$\square$ Company-owned \\
$\square$ Leased \\
$\square$ Drop-and-hook
\end{tabular}

Date

1. Print vehicle weigh ticket and record GVW

2. Perform a Level-1 inspection and record the report number

3. Perform PBBT test and record test number (see printout)

4. Print out SIRIS inspection and record the inspection number

5. Identify axle ends with SIRIS ROI problems

6. Check tires for problems such as mismatched tire heights, low pressure, etc.

$\square$ None found

$\square$ Yes, problem(s) described below:

7. Comments

Attach the following documents and place in the ORNL wall pocket:

Weigh ticket

Level-1 inspection report

PBBT results

SIRIS printout 
[This page intentionally left blank.] 


\section{APPENDIX B: VIOLATIONS ASSOCIATED WITH SIRIS}

\begin{tabular}{|c|c|c|}
\hline Reg Code & Type & Notes \\
\hline 393.44 & $\mathrm{~B}$ & NO/DEFECTIVE BUS FRONT BRAKE LINE PROTECTION \\
\hline 393.45 & $\mathrm{~B}$ & BRAKE TUBING AND HOSE ADEQUACY \\
\hline 393.40 & B & INADEQUATE BRAKE SYSTEM ON A CMV \\
\hline 393.41 & $\mathrm{~B}$ & NO/DEFECTIVE PARKING BRAKE SYSTEM ON CMV \\
\hline 393.42 & $\mathrm{~B}$ & NO BRAKES AS REQUIRED \\
\hline 393.42A & $\mathrm{B}$ & NO BRAKES ON ALL WHEELS AS REQUIRED \\
\hline 393.42B & $\mathrm{B}$ & NO/DEFECTIVE FRONT WHEEL BRAKES AS REQ \\
\hline 393.43 & $\mathrm{~B}$ & NO/IMPROPER BREAKAWAY/EMERG BRAKING \\
\hline $393.43 \mathrm{~A}$ & $\mathrm{~B}$ & NO/IMPROPER TRACTOR PROTECTION VALVE \\
\hline 393.43D & $\mathrm{B}$ & NO/DEFECTIVE AUTOMATIC TRAILER BRAKE \\
\hline 393.45 & $\mathrm{~B}$ & BRAKE TUBING AIR HOSE ADEQUACY \\
\hline 393.45B2 & B & BRAKE HOSE/TUBING CHAFFING/KINKING \\
\hline 393.45B3 & $\mathrm{B}$ & BRAKE HOSE/TUBE CONTACT EXHAUST SYSTEM \\
\hline 393.45D & $\mathrm{B}$ & BRAKE HOSE/TUBE CONNECTION \\
\hline 393.45D & $\mathrm{B}$ & BRAKE CONNECTIONS WITH LEAKS/CONSTRICT \\
\hline 393.47 & $\mathrm{~B}$ & INADEQUATE BRAKE LINING FOR SAFE STOPPING \\
\hline $393.47 \mathrm{~A}$ & $\mathrm{~B}$ & INADEQUATE BRAKES FOR STOPPING \\
\hline 393.47D & $\mathrm{B}$ & INSUFFICIENT BRAKE LININGS \\
\hline 393.47E & $\mathrm{B}$ & CLAMP OR ROTO TYPE BRAKE OUT-OF-ADJUSTMENT \\
\hline 393.48A & $\mathrm{B}$ & INOPERATIVE/DEFECTIVE BRAKES \\
\hline 393.48B1 & $\mathrm{B}$ & DEFECTIVE BRAKE LIMITING DEVICE \\
\hline 393.50 & B & INADEQUATE RESERVOIR, AIR/VACUUM BRAKES \\
\hline $393.50 \mathrm{~A}$ & $\mathrm{~B}$ & FAIL TO HAVE SUFFICIENT AIR/VACUUM RESERV \\
\hline $393.50 \mathrm{~B}$ & $\mathrm{~B}$ & FAIL TO EQUIP VEH-PREVENT RES AIR/VAC LEAK \\
\hline $393.50 \mathrm{C}$ & $\mathrm{B}$ & NO MEANS TO ENSURE OPERABLE CHECK VALVE \\
\hline 393.51 & $\mathrm{~B}$ & NO/DEFECTIVE BRAKE WARNING DEVICE \\
\hline 393.75 & $\mathrm{~T}$ & TIRES/TUBES (GENERAL) \\
\hline $393.75 \mathrm{~A}$ & $\mathrm{~T}$ & FLAT TIRE OR FABRIC EXPOSED \\
\hline 393.75A1 & $\mathrm{T}$ & TIRE-PLY OR BELT MATERIAL EXPOSED \\
\hline 393.75A2 & $T$ & TIRE-TREAD/SIDEWALL SEPERATION \\
\hline 393.75A3 & $\mathrm{T}$ & TIRE-FLAT/AUDIBLE AIR LEAK \\
\hline 393.75A4 & $\mathrm{T}$ & TIRE-CUT EXPOSING PLY/BELT MATERIAL \\
\hline 393.75B & $\mathrm{T}$ & TIRE-FRONT TREAD DEPTH LESS THAN 4/32 INCH \\
\hline $393.75 \mathrm{C}$ & $T$ & TIRE-OTHER TREAD DEPTH LESS THAN 2/32 INCH \\
\hline 393.75D & $\mathrm{T}$ & TIRE-BUS REGROOVED/RECAP ON FRONT WHEEL \\
\hline 393.75E & $\mathrm{T}$ & TIRE-REGROOV ON FRNT OF TRUCK/TRUCK/TRAC \\
\hline $393.75 F$ & $\mathrm{~T}$ & TIRE-LOAD WEIGHT RATING/UNDER INFLATED \\
\hline $393.75 \mathrm{~F} 2$ & $\mathrm{~T}$ & TIRE-UNDER-INFLATED \\
\hline $393.75 F 4$ & $T$ & FLAT TIRE \\
\hline 393.209D & $\mathrm{R}$ & LOOSE BEARING \\
\hline 396.3A1B & $\mathrm{B}$ & BRAKES (GENERAL) \\
\hline 396.3A1BA & $\mathrm{B}$ & BRAKE-OUT OF ADJUSTMENT \\
\hline 396.3A1BC & $\mathrm{B}$ & BRAKE-AIR COMPRESSOR VIOLATION \\
\hline 396.3A1BD & B & BRAKE-DEFECTIVE BRAKE DRUM \\
\hline
\end{tabular}




\begin{tabular}{|l|l|l|}
\hline \multicolumn{1}{|c|}{ Reg Code } & Type & \multicolumn{1}{c|}{ Notes } \\
\hline 396.3A1BH & B & BRAKE-HOSE/TUBE DAMAGE/LEAKING \\
\hline 396.3A1BL & B & BRAKE-RESERVE SYSTEM PRESSURE LOSS \\
\hline
\end{tabular}




\section{APPENDIX C: SIRIS PROBLEM LOG SHEET}

This log sheet is to be used when any problem with SIRIS occurs such as weather related issues, detection issues, or any other issues that cause the system to not function properly.

\begin{tabular}{|l|l|l|}
\hline Date & Time & \\
\hline $\begin{array}{l}\text { Trooper (in case of additional questions } \\
\text { concerning SIRIS issue) }\end{array}$ & \\
\hline Describe the issue with SIRIS: \\
\hline Action(s) performed to resolve issue: \\
\hline
\end{tabular}

\begin{tabular}{|l|l|l|}
\hline Date & Time & \\
\hline $\begin{array}{l}\text { Trooper (in case of additional questions } \\
\text { concerning SIRIS issue) }\end{array}$ & \\
\hline Describe the issue with SIRIS: \\
\hline Action(s) performed to resolve issue: \\
\hline
\end{tabular}

\begin{tabular}{|l|l|l|}
\hline Date & Time & \\
\hline $\begin{array}{l}\text { Trooper (in case of additional questions } \\
\text { concerning SIRIS issue) }\end{array}$ & \\
\hline Describe the issue with SIRIS: \\
\hline Action(s) performed to resolve issue: \\
\hline
\end{tabular}


[This page intentionally left blank.] 


\section{APPENDIX D: SIRIS FIELD OPERATIONAL TEST QUESTIONNAIRE}

The purpose of this questionnaire is to get a sense of the overall end-user acceptance of SIRIS. Answers and comments will be anonymously included in the Final Report.

1. Briefly describe your experience working with SIRIS.

2. How effective has SIRIS been in screening vehicles for inspection? Briefly explain why or why not.

3. What changes (if any) would you make to the SIRIS system including the way the information is displayed on the user screen?

4. Do you believe that a system such as SIRIS is ready for national deployment? Explain.

5. How would you envision a system as such SIRIS being used in your operations if it were a permanent device? 
[This page intentionally left blank.] 


\section{APPENDIX E: TENNESSEE HIGHWAY PATROL QUESTIONNAIRE ANSWERS}

1. Briefly describe your experience working with SIRIS.

a. Have used on multiple occasions as overtime grant - collection of data etc.

b. Have used on multiple occasions - grant overtime, etc. grant research etc.

c. Interaction at the Greene Co. Scales. I have spent more time working on it than working with it.

d. Use it every day that it works.

e. SIRIS has been installed at our facility. I have conducted numerous inspections based on the SIRIS indicators.

2. How effective has SIRIS been in screening vehicles for inspection? Briefly explain why or why not.

a. Very small percentage of accuracy. Very sound in theory and idea, however I believe it needs to be greatly fine-tuned.

b. Detect a potential lack of performance, needs more stability, application method has signs of impairment. I have multiple concerns into the testing of the program, over "screening" versus "inspecting" vehicles have become a hot topic.

c. Somewhat...you have to learn to ignore the alarm and read the temperatures yourself and take more things like weight of load into consideration.

d. Is a good screening tool when you learn to draw your own judgments from the alerts.

e. About $20 \%$ defects indicated have been found during my inspections, however the machine has proven to be very environmentally sensitive to rain and temperature differences. I have also had a lot of difficulty in keeping the computer and cameras operating.

3. What changes (if any) would you make to the SIRIS system including the way the information is displayed on the user screen?

a. None - The design \& display of information is very good (just the accuracy).

b. None. Just look at its operational policies to ensure that it has provided appropriate guidance to enforcement personnel so that they are able to make uniform decisions throughout.

c. I would make it more reliable and consistent so trooper could depend on it to work. The parameters would be reworked for a more accurate defect rate when alarm is obtained.

d. Make the unit more robust. No so sensitive to weather. Screen display is great when working. More work is needed to stop false alarms.

e. Display is OK.

4. Do you believe that a system such as SIRIS is ready for national deployment? Explain.

a. No - At this point I believe it takes more time to screen SIRIS than it does to walkout side \& screen the vehicle personally. 
b. Yes. Truly it's a rewarding experience and reinforces your belief that the alliance is headed in the right direction. I encourage others to get involved and take on responsibility. You will learn a lot, have a greater appreciation for SIRIS, and want to contribute to furthering its mission.

c. No. Too much time spent keeping system up and running. Disconnected socket, no picture, and showing 15 axles when truck only has 5 or showing two when truck has 5 .

d. Not reliable enough at this time.

e. No. The system is unreliable. It won't stay operational and continuously needs to be reset. Ambient temperature makes it fair weather only device. It also has too many false positives.

5. How would you envision a system as such SIRIS being used in your operations if it were a permanent device?

a. At present it is an OK tool. If SIRIS was more accurate and dependable, it would be a great tool. [If] It could determine $100 \%$ of the vehicles we would check or inspect.

Bottom line - If it was more accurate it would be invaluable. As it is, I believe a quick walk around the vehicle is more beneficial.

b. I envision the smart infrared inspection system (SIRIS) as [it] saves time for the inspectors and increases inspector productivity. I would benefit greatly because (SIRIS) has the potential to automatically target unsafe trucks and buses for further inspection by roadside/scale complex thus reducing the likelihood of these vehicles being involved in crashes and vehicle fires. Knowing I had a system like (SIRIS) would have potential to save hundreds of staff hours by identifying unsafe vehicles for inspection.

c. It has potential of being a great screening tool. It could help you spend your time checking trucks that need to be checked. It seems to be in a really early stage of development

d. Great screening tool.

e. The idea of temperature relating to vehicle defects is a sound theory if you have a reliable and efficient method of determination. This would allow for more time to be spent with problem vehicles and less time with good ones resulting in more unsafe operators being removed from service. 
APPENDIX F: SIRIS OPERATIONS MANUAL

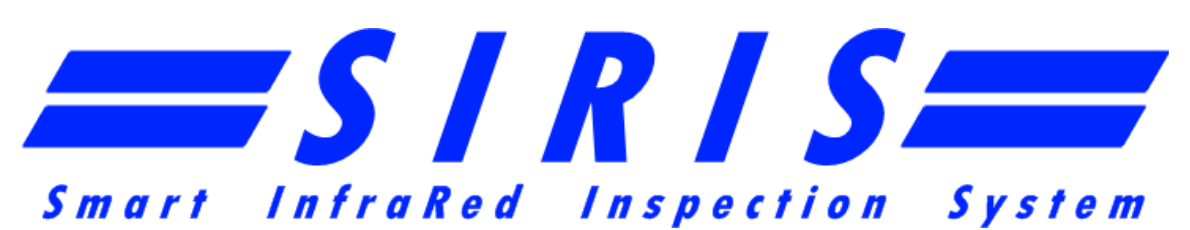

OPERATIONS MANUAL

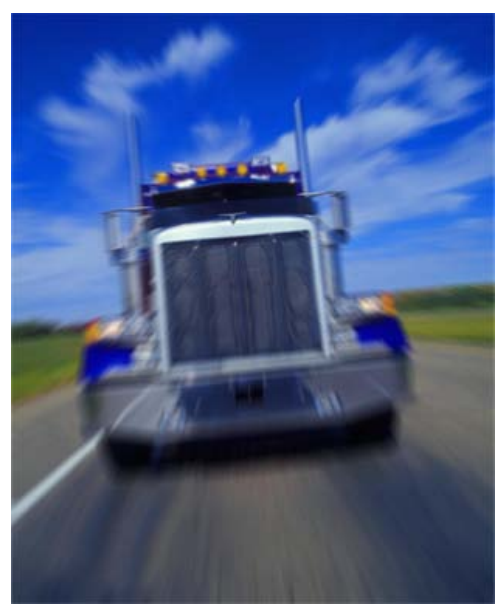




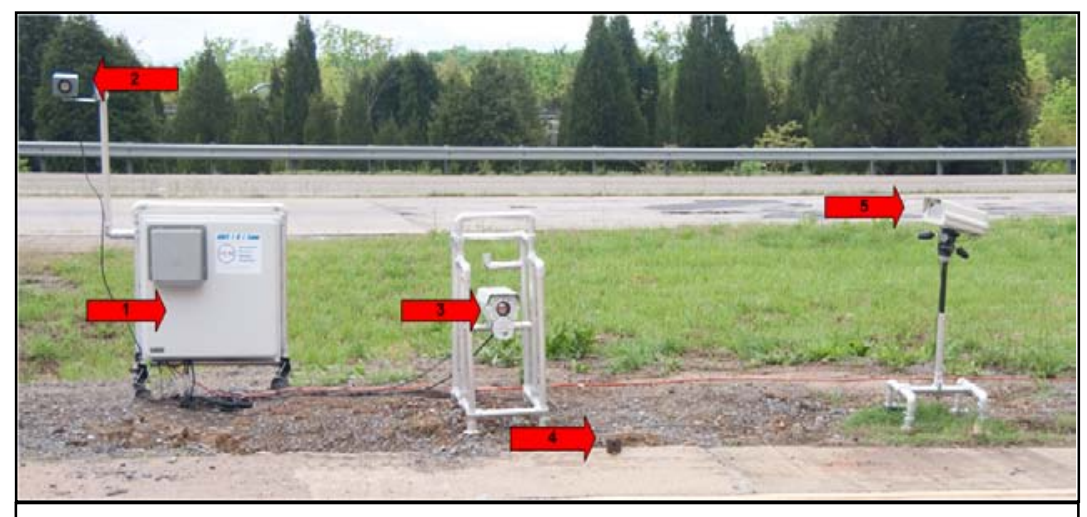

This photo shows the typical configuration of the SIRIS system. The components, which are detailed below, are: 1 . Main unit, 2. Ultrasonic Detector, 3. Infrared Camera (a second infrared camera is located on the other side of the vehicle and is not shown), 4. Optical Trigger (the other half of the optical trigger system is located on the other side of the vehicle and is not shown), and 5 . Vehicle Camera. Not
International Electronic Machines Corporation

\section{SYSTEM} DESCRIPTION GENERAL DESCRIPTION The Smart InfraRed Inspection System (SIRIS) is a tool designed to assist inspectors in determining which vehicles passing through the system are in need of further inspection

by measuring the thermal data from the wheel components. SIRIS is setup as a permanent installation in a configuration similar to the photo above though your system could vary. IEM engineers will work with inspection personnel to find the best placement for the system. This system is an advisory system and does not replace the inspection process.

\section{COMPONENT DESCRIPTION}
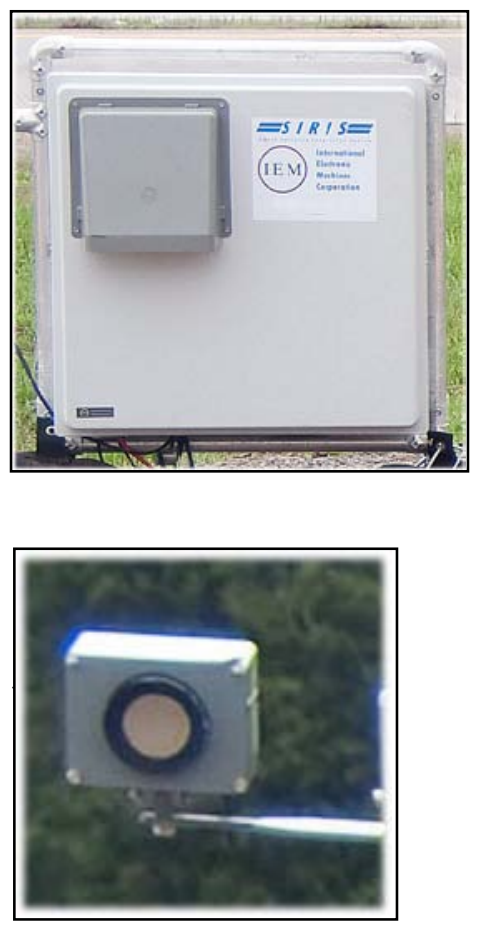

The Main Unit is a rugged case that holds the operating computer for the system components. This computer is linked to User Interface computer housed in the scale house or other protected structure. The User Interface computer collects data, issues alerts and displays the User Interface.

The ultrasonic detector is triggered when a vehicle enters the system. This activates the system to capture thermal data. 


\section{InfraRed Camera}

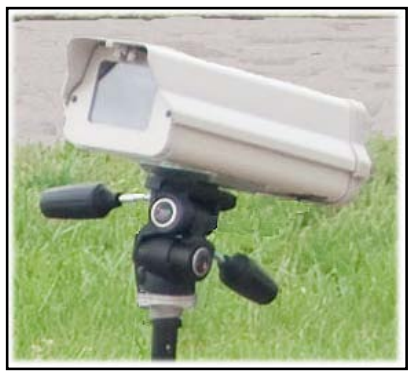

\section{Optical Trigger}

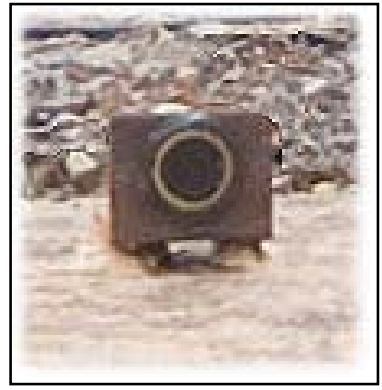

\section{Vehicle Camera}

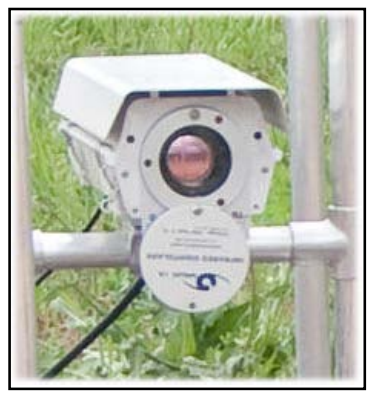

\section{User Interface Computer}

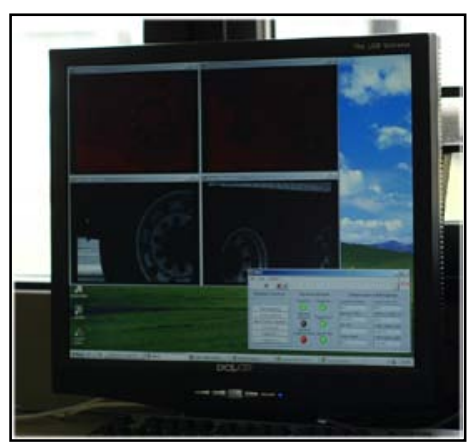

InfraRed imaging is used to determine the heat or lack of heat of each of three regions of interest. Regions of interest are explained later in this section. Two infrared cameras are located on opposite sides of the vehicle so that both sides of each axle are measured (this is not pictured in the system photo on page 1).

The optical trigger activates the infrared camera when the tires are within the photographic frame. This allows the system to capture the wheel in such a way that it is centered in the frame and easily identified by the system. The optical trigger consists of two pieces which face each other across the lane. An invisible beam of light is sent from one to the other. When the beam is broken, the system is triggered.

This camera takes a photo of the vehicle as it enters the system. This photo identifies the vehicle as it moves through the inspection site. This picture is shown on the user interface when this file is viewed.

The User Interface computer is housed within the inspection facility and displays the data gathered from the passing vehicles. The User Interface is described in detail below. 


\section{SIRIS IN OPERATION}

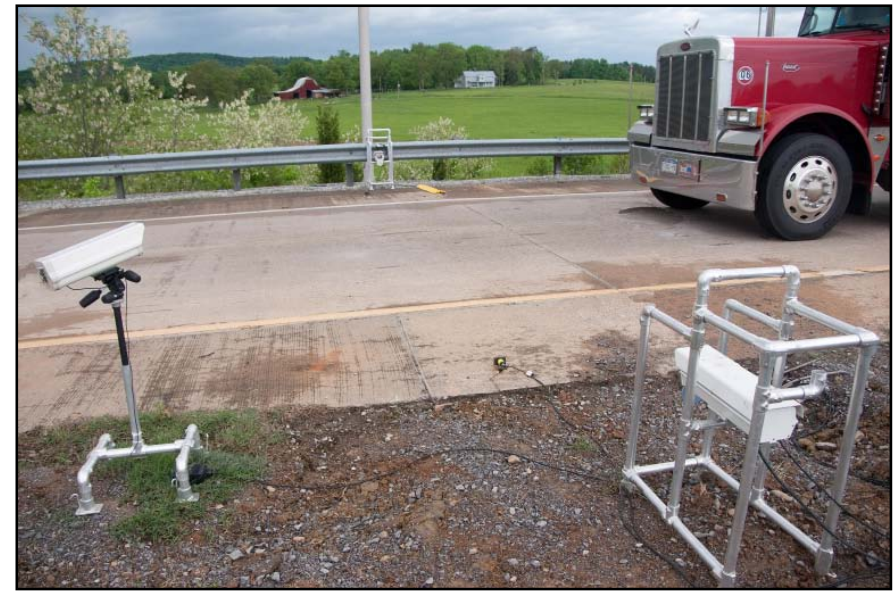

As a vehicle enters the system, the Ultrasonic Detector triggers the system to begin measuring. Starting the system is detailed in the Getting Started Section.

The Vehicle Camera takes a photo of the front of the vehicle as it is triggered by the ultrasonic detector.

The vehicle moves past the Optical Trigger which triggers the Infrared Camera.

Thermal images of each axle is captured on the right and left sides of the vehicle.

SIRIS maps the Regions of Interest. To the operator, these areas are designated with circles for the tire, brakes, and bearings. Within these regions of interest, SIRIS measures the temperatures as compared to the other components and the ambient temperature. It applies the criteria of its programming and flags any component that is outside of these measurements. This process is accomplished within milliseconds. 


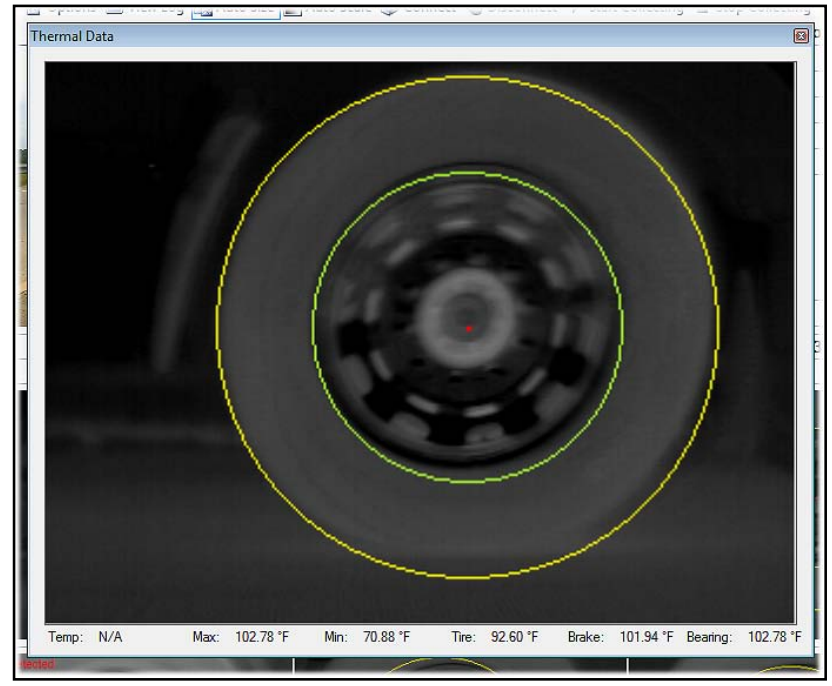

\section{REGIONS OF INTEREST}

SIRIS measures the thermal data for each outside wheel on both the left and right sides of the vehicle. The data is collected from three areas of the wheel which the system identifies as Regions of Interest (ROI). These regions are the hub, rim, and tire. The software represents these areas on the images on the User Interface as a yellow circle for the tire, green circle for the rim, and a red dot for the hub.

The correct mapping of the ROI (pictured above) enables SIRIS to evaluate the thermal data for each component from the identification of these areas. By looking at the rim, thermal information on the brakes can be found. The hub is measured to determine the state of the wheel's bearings, and, of course, the thermal data for the tire is collected from within the tire area. The results of the gathered data are discussed later in this manual.

If an alert is issued by the system, the operator should check that the ROI have been correctly identified first. The ROI could be identified incorrectly which could lead to false alerts.

While the ROI are identified correctly a majority of the time, ROI can be misinterpreted, misidentified or not identified. Below is a list of some of the most common of these misses: 
- ROI Misidentified - As in this photo, the system may misinterpret the image and identify the regions incorrectly. In this example, the tire region is identified as the rim and the brake region is identified as around the hub. In this case, any alerts would most likely be incorrect.

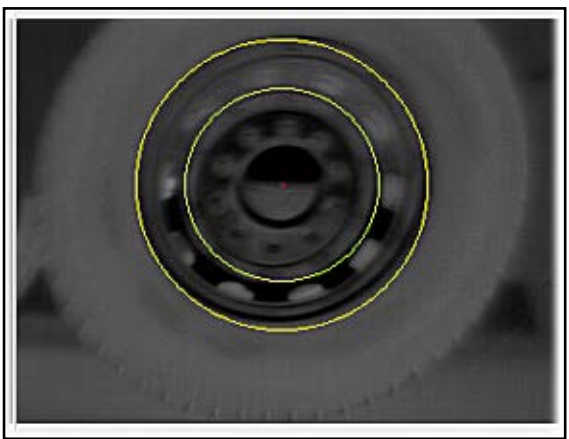

- No ROI Identified - If the wheel image is not fully in the frame or if the image is significantly out of focus, SIRIS may not be able to identify any of the regions. The system will mark the image as 'Nothing Detected' as in the example on Page 8.

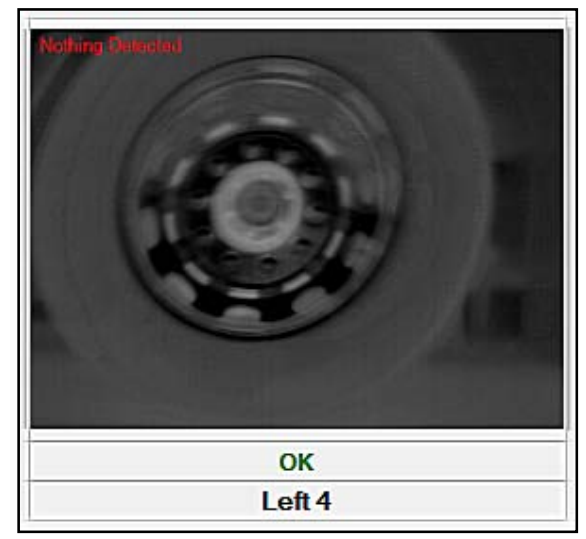

- Skewed ROI - Out of focus images may also result in a skewed ROI. In some cases, the ROI is not centered on the wheel but is still covering a majority of it. In this case, the thermal data is usable and correct.

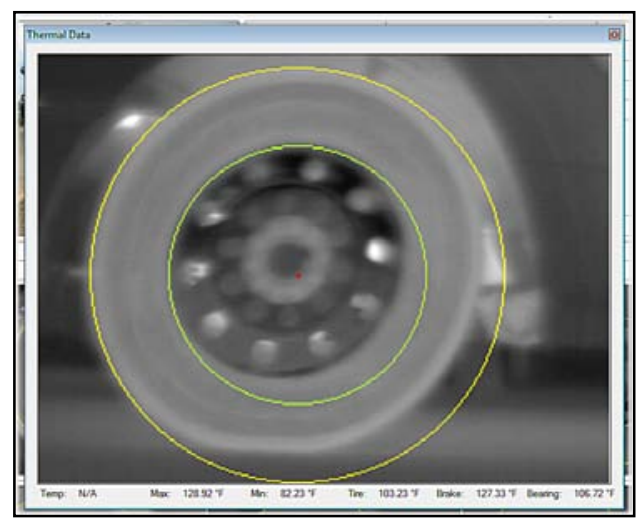


If the ROI is too skewed, it will cover more of the surrounding truck or the road rather than the wheel. In this case, the data is not usable and any alerts should be disregarded.

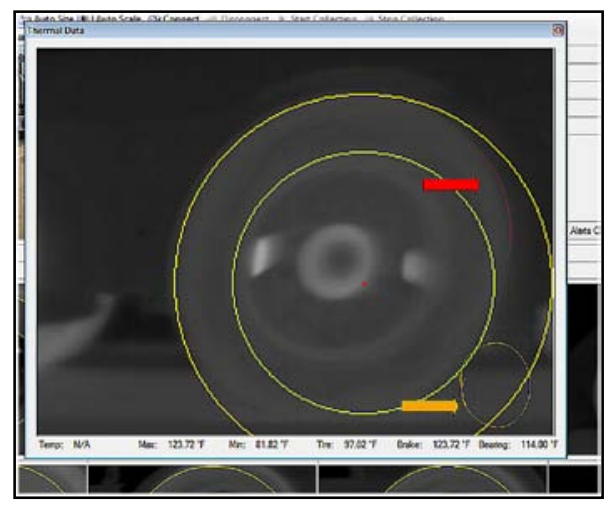




\section{GETTING STARTED}

\section{SYSTEM START UP}

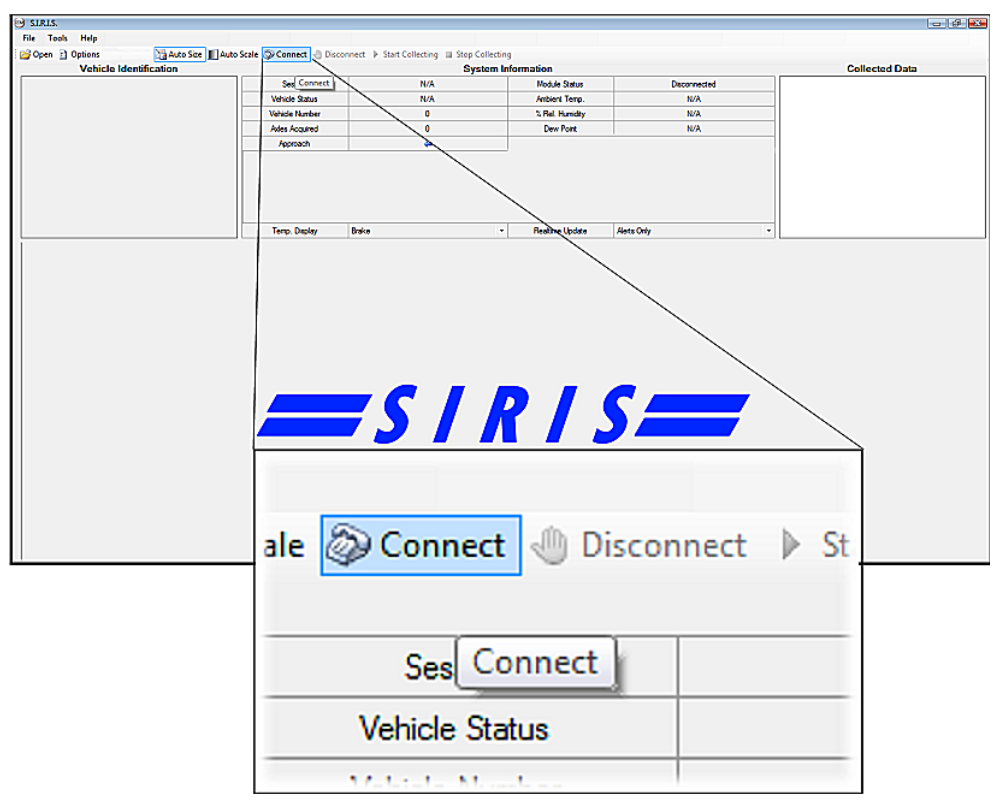

The SIRIS system is designed to run continuously. The following instructions should be followed when all of the components are powered on. If the components are not powered on, see the troubleshooting section of this manual.

Open the SIRIS program on the user interface computer, which is located in the inspection facility or other enclosure, by clicking on the SIRIS icon on the desktop.

Once the program has started, connect to the Main Unit by clicking on the “Connecting” button. The Module Status will change to Connected.

A new session is started when the system is connected. A session is considered all of the collected vehicle data for a selected period. A session is used to identify the folder in which to look for collected data. More information on Sessions can be found in the User Interface Basics section.

In order to start collecting, click the "Start Collecting” button. The system will start collecting data from passing vehicles and the Module Status (see the User Interface Basics section for more information on Module Status) will state Starting and then Collecting.

The system is now operating and collecting data. This data is saved on the computer in easily accessed files. See the User Interface Basics section for more information. 


\section{STOP COLLECTING}

In order to stop collecting, click "Stop Collecting”. The Module Status will state Connected (Not Collecting). The system is still operating but it will not collecting any data from passing vehicles.

\section{DISCONNECTING THE SYSTEM}

To disconnect the system from the Main Unit, click on the "Disconnect" button on the top toolbar of the User Interface. The Module Status will state Disconnected.

\section{END SESSION}

In order to manually end the current session, collecting must be stopped and the system disconnected. This will end the session. When the system is reconnected, a new session will be initiated.

A new session is also periodically started by the system to maintain manageable files. This is described further in the User Interface Basics section.

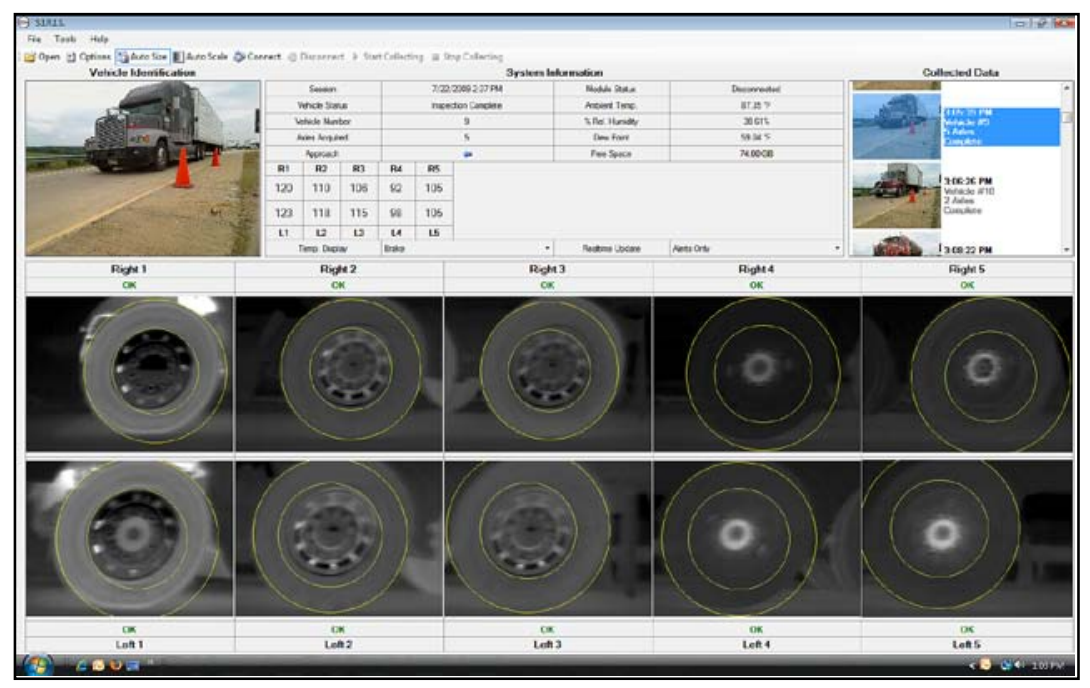

\section{USER INTERFACE BASICS}

The User Interface, shown above, is the main screen of the SIRIS system and all user accessible features are controlled from this interface. The various areas and their uses are described below. For better understanding, the screen is split into three sections. 


\begin{tabular}{|c|c|}
\hline \multicolumn{2}{|c|}{ Sysiem in } \\
\hline Session & $7 / 22 / 20092: 37$ PM \\
\hline Vehicle Status & Inspection Complete \\
\hline Vehicle Number & 7 \\
\hline Axdes Acquired & 5 \\
\hline Approach & 年 \\
\hline
\end{tabular}

\section{SESSION}

A session is initiated when the system is connected and is the collection of the vehicle data for that period of time. When an operator needs to view data on a vehicle that passed through during a different session, (s)he will go to the SIRIS files and look for the date (year, month, and day) and the time (hour, minute, second). A session can be ended manually by disconnecting the system. It will also automatically end a session after 150 cars has passed through.

\section{VEHICLE STATUS}

The Vehicle Status changes as the vehicle moves through the system. As the vehicle is being measured, the status is listed as Vehicle In System. When the vehicle has passed by and the inspection data is stored, the status is listed as Inspection Complete. If an error occurred during the SIRIS inspection or the vehicle stopped in the middle of the system, the status would state Inspection Incomplete.

\section{VEHICLE NUMBER}

SIRIS assigns a sequential number to each vehicle that passes through during that session. The count is reset with each new session.

\section{AXLES ACQUIRED}

This shows the number of axles for the vehicle.

\section{APPROACH}

This indicates the direction in which vehicles will enter the system. 


\begin{tabular}{|c|c|}
\hline Module Status & Disconnected \\
\hline Ambient Temp. & $87.35{ }^{\circ} \mathrm{F}$ \\
\hline \% Rel. Humidity & $38.61 \%$ \\
\hline Dew Point & $59.04{ }^{\circ} \mathrm{F}$ \\
\hline Free Space & $74.19 \mathrm{~GB}$ \\
\hline
\end{tabular}

\section{MODULE STATUS}

Module status lists the status of SIRIS. The status of the system when the operator first logs on to the system is Disconnected. Once connected, the status is listed as Connected. The status changes to Collecting once the system is told to start collecting data. Connecting and Start Collecting as well as Disconnecting the system are explained in greater detail in the section titled Getting Started in this manual.

\section{AMBIENT TEMPERATURE}

The ambient temperature is the air temperature outside. The gauge for this is on the underside of the Main Unit. The system uses ambient temperatures to determine whether an alert should be issued for the vehicle in the system.

\section{\% REL. HUMIDITY}

The relative humidity, like the ambient temperature, is based on the conditions at the Main Unit.

\section{DEW POINT}

The Dew Point is based on a formula using the ambient temperature and the relative humidity.

\section{FREE SPACE}

Free space lists the amount of space available on the User Interface computer for additional sessions. When the space gets too low, the word LOW appears in blue next to the number. If the free space becomes low, the operator should either save old data to a disk or delete it from the system as dictated by site rules.

Free space also serves as a link to the saved files. The free space number, in this example: 74.19 GB, is a hyperlink to the location of the session files. By clicking on the numbers, the saved files will be open for easy access. 


\begin{tabular}{|c|c|c|c|c|c|c|}
\hline \multicolumn{4}{|c|}{ thiousin } & & \multicolumn{2}{|c|}{1} \\
\hline R1 & $\mathrm{R} 2$ & R3 & R4 & R5 & & \\
\hline 126 & 120 & 113 & 126 & 131 & & \\
\hline 127 & 134 & 126 & 133 & 146 & & \\
\hline L1 & L2 & L3 & L4 & L5 & & \\
\hline \multicolumn{3}{|c|}{ Temp. Display } & \multicolumn{2}{|l|}{ Brake } & r & \\
\hline & \multicolumn{2}{|c|}{ Right 2} & \multicolumn{2}{|l|}{\begin{tabular}{|l} 
Tire \\
Brake
\end{tabular}} & & 3 \\
\hline & \multicolumn{2}{|c|}{ OK } & \multicolumn{2}{|l|}{ Bearing } & & \\
\hline
\end{tabular}

\section{TEMPERATURE DISPLAY BOX}

The temperature display box presents the gathered data to the operator. The data is identified by the side and axle number. The temperature below that identifier is the number for that axle, side and component. To change which component of the wheel is being feature in the Temperature Display Box, see below. More information on using the information displayed here is available in the Alerts section of this manual.

\section{TEMPERATURE DISPLAY MENU}

The temperature display menu allows the operator to change the data group that is being displayed. By clicking on the drop down menu, the operator can switch between the three components that are measured by SIRIS: tire, brake, or bearing. The information that the operator looks at should be determined by the issued alert. The default for this menu is brake.

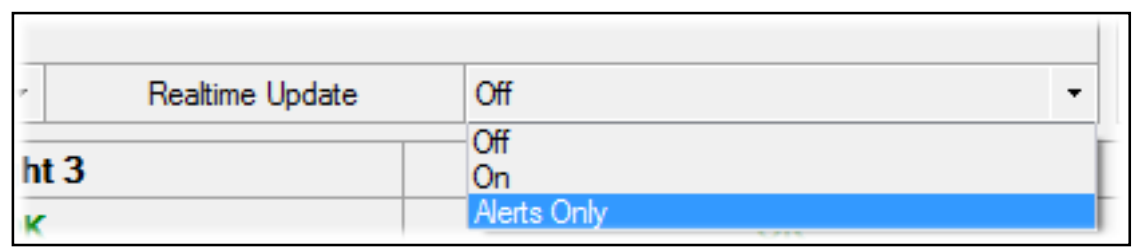

\section{REALTIME UPDATES}

This drop down menu is used to set when the system updates the image window. The screen could update with new images for every vehicle is measured as it is measured, only when an alert is issued while a vehicle is being measured, or not at all. The operator may wish to turn the updates off while studying a previously collected file as the update will remove the previous inspection images from the screen. If the updates are set to On, every new vehicle will cause the screen to update. If the Alerts Only is chosen, the screen updates only when a problem is detected with a passing vehicle. All files are saved regardless of the setting for Realtime Updates. 


\section{CONNECT}

This button allows the operator to connect the user interface computer to the Main Unit and begin a session. This function is detailed in the Getting Started section of this manual.

\section{DISCONNECT}

Clicking on Disconnect will end the session and will disconnect the user interface computer from the Main Unit. More detail on this can be found in the Getting Started section of this manual.

\begin{tabular}{|c|c|}
\hline \multicolumn{2}{|l|}{ nformation } \\
\hline Module Status & Connected (Not Collecting) \\
\hline Ambient Temp. & $66.38^{\circ} \mathrm{F}$ \\
\hline$\%$ Rel. Humidity & $43.20 \%$ \\
\hline D n.... D - ins & AO300 \\
\hline
\end{tabular}

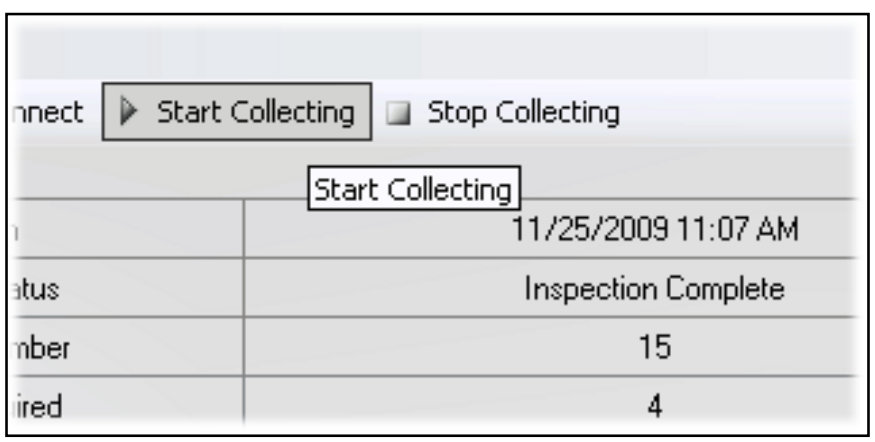

\section{START COLLECTING}

Once connected, the user must select 'Start Collecting' in order to begin a new session. The system will not image any vehicles passing through the system until 'Start Collecting' is selected and the cameras have had a few moments to start. This is detailed in the Getting Started section of this manual.

\section{STOP COLLECTING}

If the operator wishes to stop collecting data, Stop Collecting' is chosen. The system will no longer measure or collect data from passing vehicles. This is often used if the inspection site is already full. The Getting Started section has more detail on this function. 
The File drop down menu located in the top toolbar allows the operator to open a single vehicle file or load an entire session back onto the system. This can allow the operator to return to a session to view the vehicles and alerts if needed. The sessions are labeled by the date and time the session was initiated. Single vehicle files are identified by the vehicle number and can be found in the Session files.
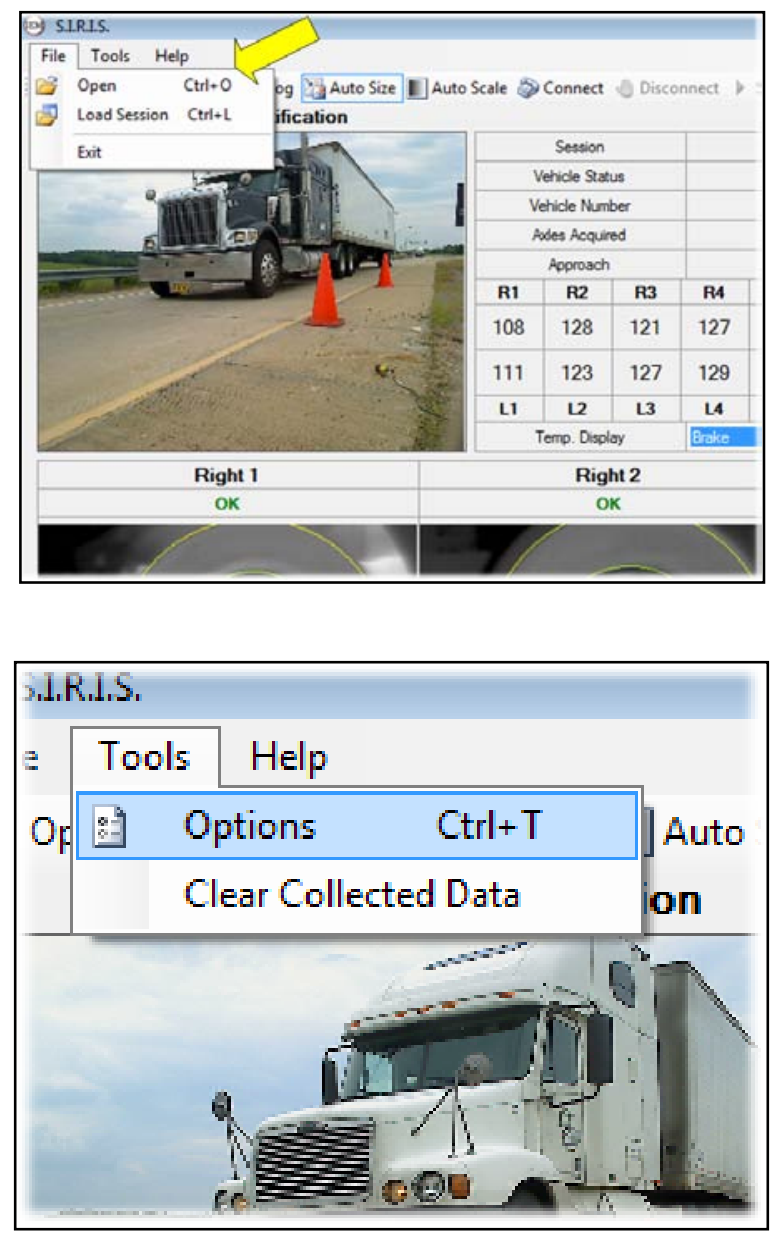

TOOLS

Tools, also located in the top toolbar, offers the operator two important functions within the SIRIS system. From this drop down menu, Options are made available for the display and alarm signals. These options are detailed below. From Tools, an operator can also select "Clear Collected Data”.

Clear Collected Data will clear the vehicle information in the Collected Data Box (detailed later in this section). This will not delete the data from the computer. While the data will not be shown in the Collected Data Box, the data is still saved on the computer. An operator may elect to clear the collected data at the beginning of each shift to make finding a recent vehicle's information easier. SIRIS will hold up to 150 
vehicle entries in the collected data box. After that number is achieved, SIRIS will begin to drop vehicles off the list to make room for new data entries. Again, this information is not deleted from the computer.

\section{OPTIONS}

\section{DISPLAY}

\section{Temperature Scaling}

Temperature Scaling allows the operator to change the look of the displayed images by manually making them darker or lighter in appearance. Later in this section, Auto Scale is described which instructs the machine to scale the images according to the Auto Scale Low and High settings. Temperature scaling should be used to enhance an image for the operator as needed.

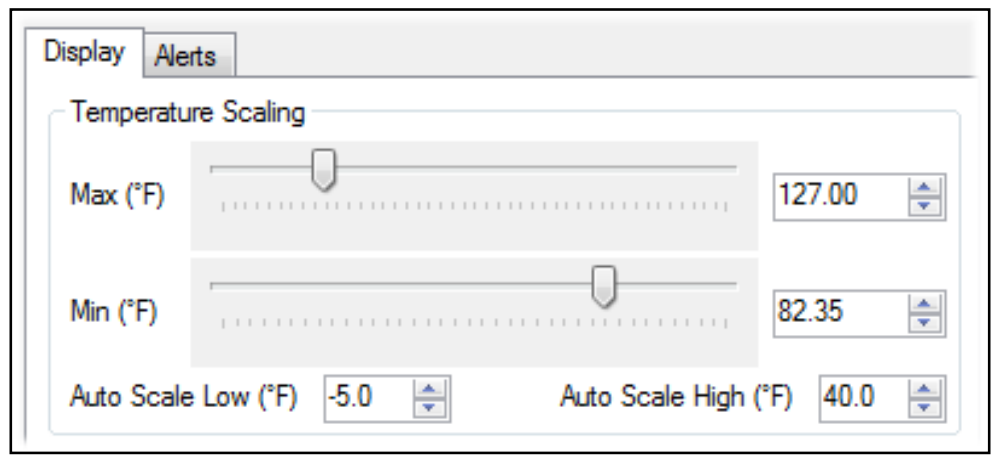

\section{Image Display}

Color Palette: The images in SIRIS are generally viewed by the operator in the Gray color palette. The operator can, however, choose a different color scheme such as Autumn (reds and oranges), HSV (neon rainbow) or Jet (blues and greens) from the drop down menu. Changing the color scheme for the images does not alter the operation of the system.

Show Detected Regions: Regions of Interest, covered earlier in this manual, are denoted by a yellow and green circle and a red dot on the displayed images. This feature can be turned off by un-checking this box. Turning off the "Show Detected Regions" feature will not affect the operation of the SIRIS system. Before turning off this feature, please read the section on Tire, Brake and Bearing Alerts in this manual.

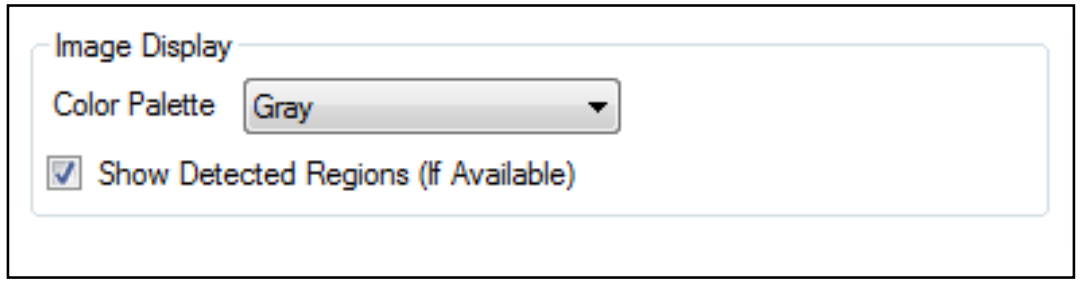




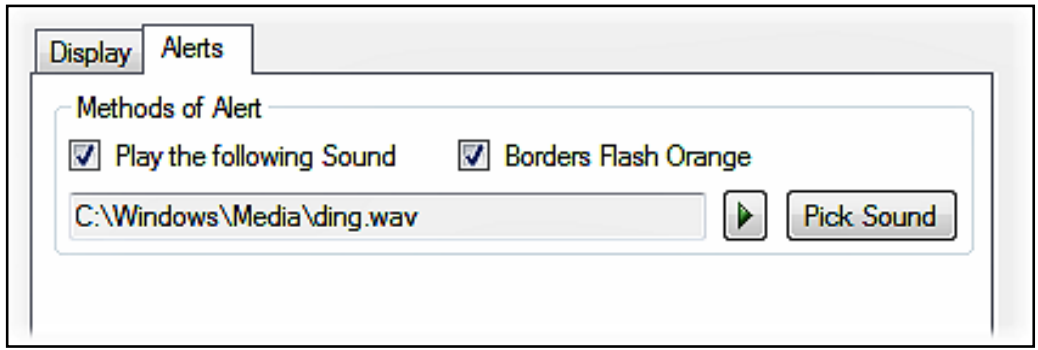

\section{ALERTS}

\section{METHODS OF ALERTS}

When a wheel component is determined to have a possible problem, SIRIS issues an alert. The default for the alert signal is an audible signal and flashing bars on the display.

The audible signal can be turned off by un-checking the "Play the Following Sound" checkbox. The audible sound can also be changed by the operator by clicking the "Pick a Sound" button. This opens up a menu with different sounds to choose from. Changing the sound or turning off the audible alert signal will not affect the operation of SIRIS.

The visual alert for SIRIS consists of a flashing orange bar on the top and bottom of the image display area. The operator can disable the visual alert by un-checking the "Borders Flash Orange" box. Turning off the visual alert will not affect the operation of SIRIS.

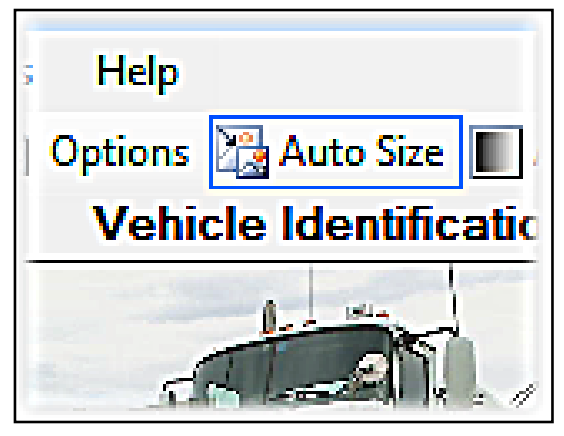

\section{AUTO SIZE}

The Auto Size feature sizes the images to fit in the image display area. Up to 5 axles can be displayed at one time. Images that have been auto sized are reduced or enlarged (depending on number of axles) to cover the image display area. 


\section{AUTO SCALE}

Auto Scale adjusts the contrast of the images in the display area in reference to the temperature information. If images are displayed that appear too dark or light, auto scale can adjust the images to more accurately reflect measurements. Using Auto Scale will not affect the measured temperatures and is strictly for viewing purposes.
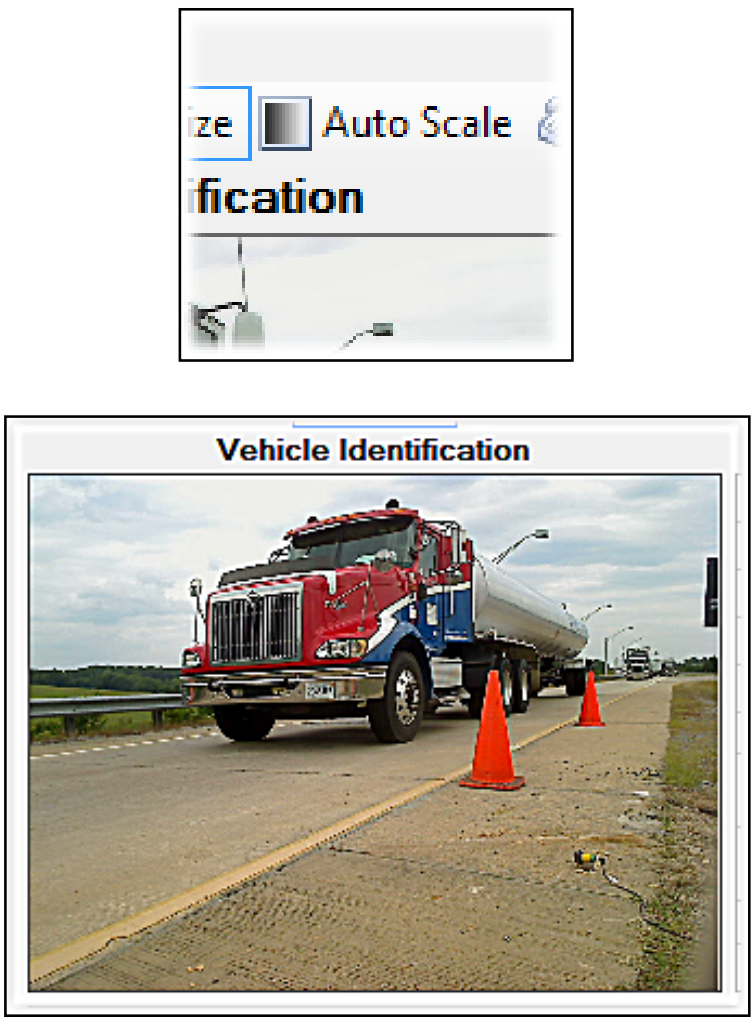

\section{VEHICLE IDENTIFICATION BOX}

The Vehicle Identification Box displays the image that was captured by the Vehicle Camera. This photo is stored along with the measurements to aid inspectors in vehicle identification. 


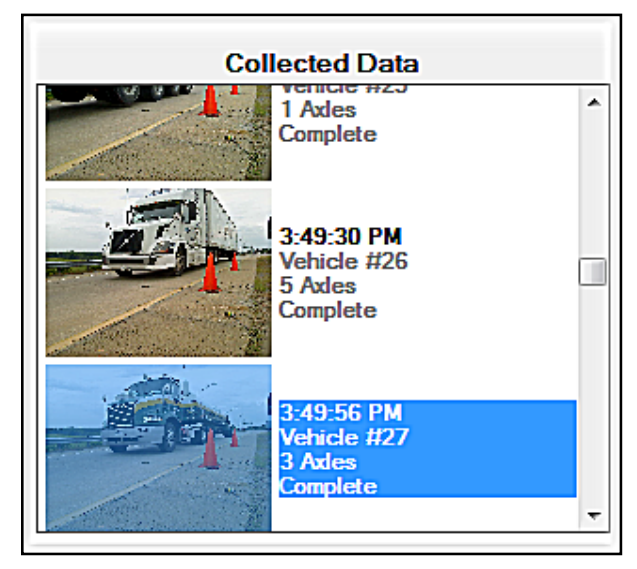

\section{COLLECTED DATA BOX}

Each vehicle that passes through the system generates an inspection report. The Collected Data Box displays all files for the current or loaded session. Each vehicle is displayed with its photo, recorded time, vehicle number, number of axles, and the status which will be Completed, Alert, or Incomplete.

An operator can view the wheel images for a vehicle by clicking on its photo. Information on clearing this data collection can be found in the Tools description.

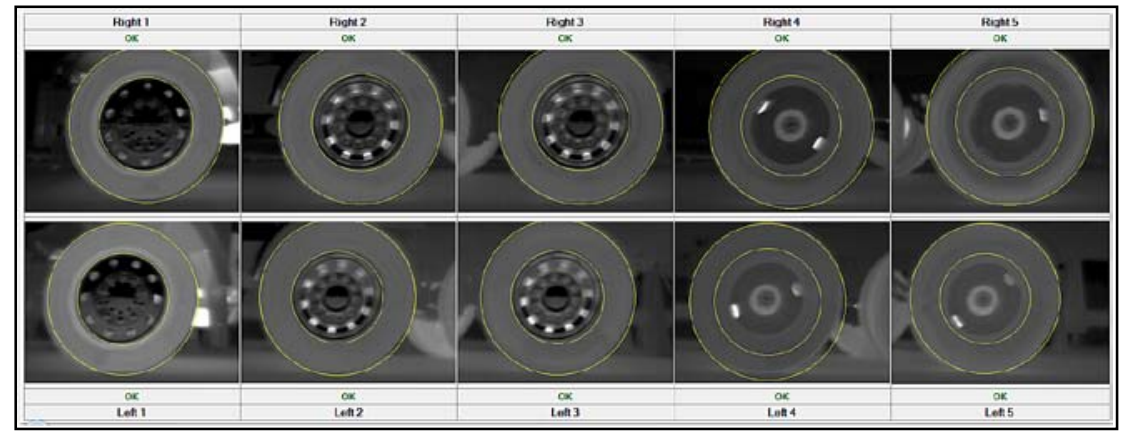

\section{IMAGE DISPLAY AREA}

The Image Display Area is located in the lower half of the User Interface. The images that are generated by SIRIS are shown here with the determined Regions of Interest (if enabled and available) and any issued alerts.

The operator can get more detailed temperature information by single clicking on an image. This will open up a new window with a close up view of that tire. By moving the pointer around on the image, the operator can see the temperature reading taken by SIRIS for any specific point. You can close the thermal data window by double clicking on the image or on the red ' $x$ ' in the right hand corner. 

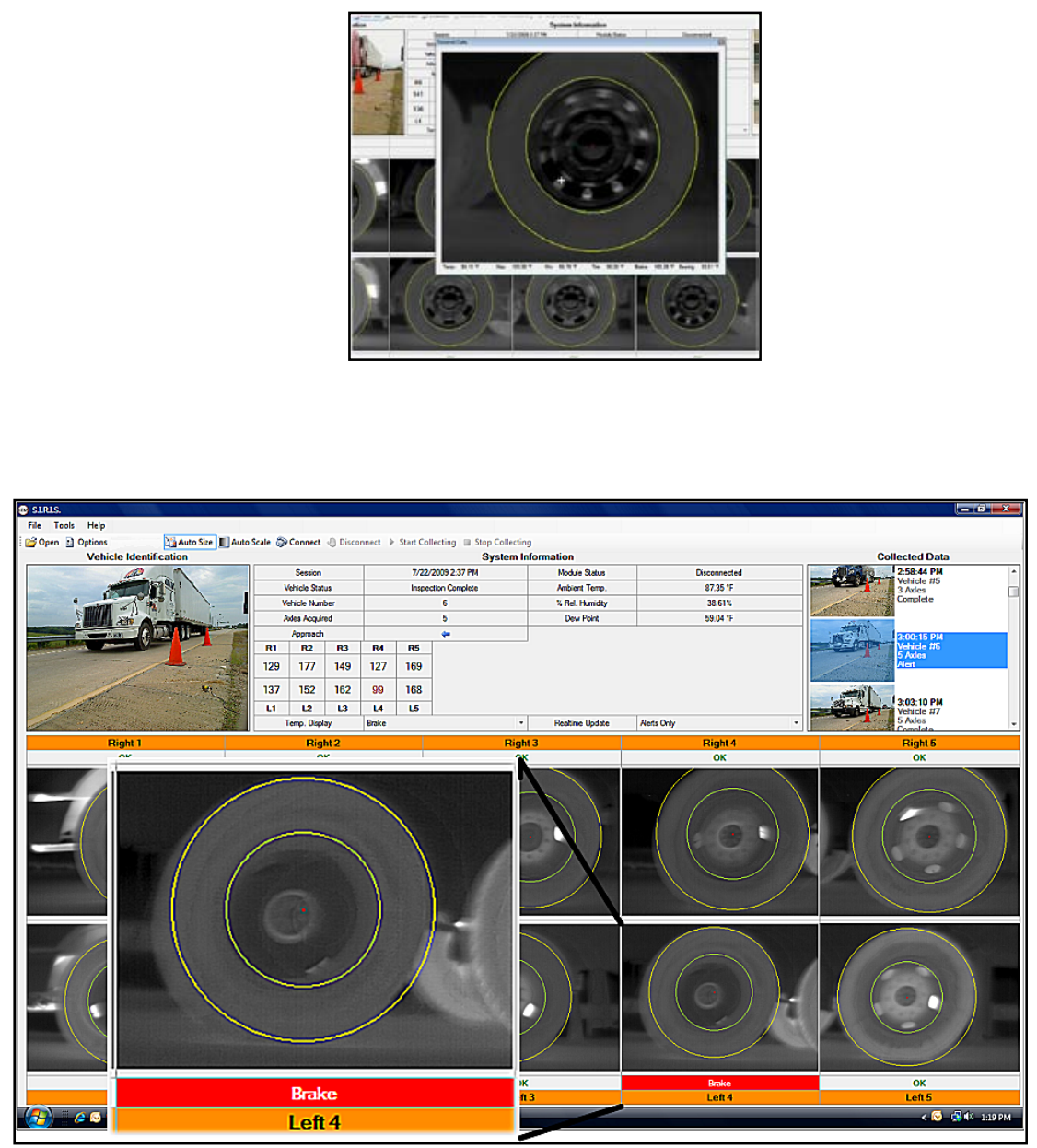

\section{ALERTING SYSTEM}

When the SIRIS system discovers an anomaly with a tire, brake or bearing, it issues an alert. The alert consists of an orange bar on the top and bottom of the image window which flashes on and off for a specified time, a red bar above or below the image that triggered the alert, and an audible signal.

As described in the User Interface Basics section of this manual, the audible and visual alarms can be customized.

SIRIS is an advisory system. All alerts should be followed up by the operator. 


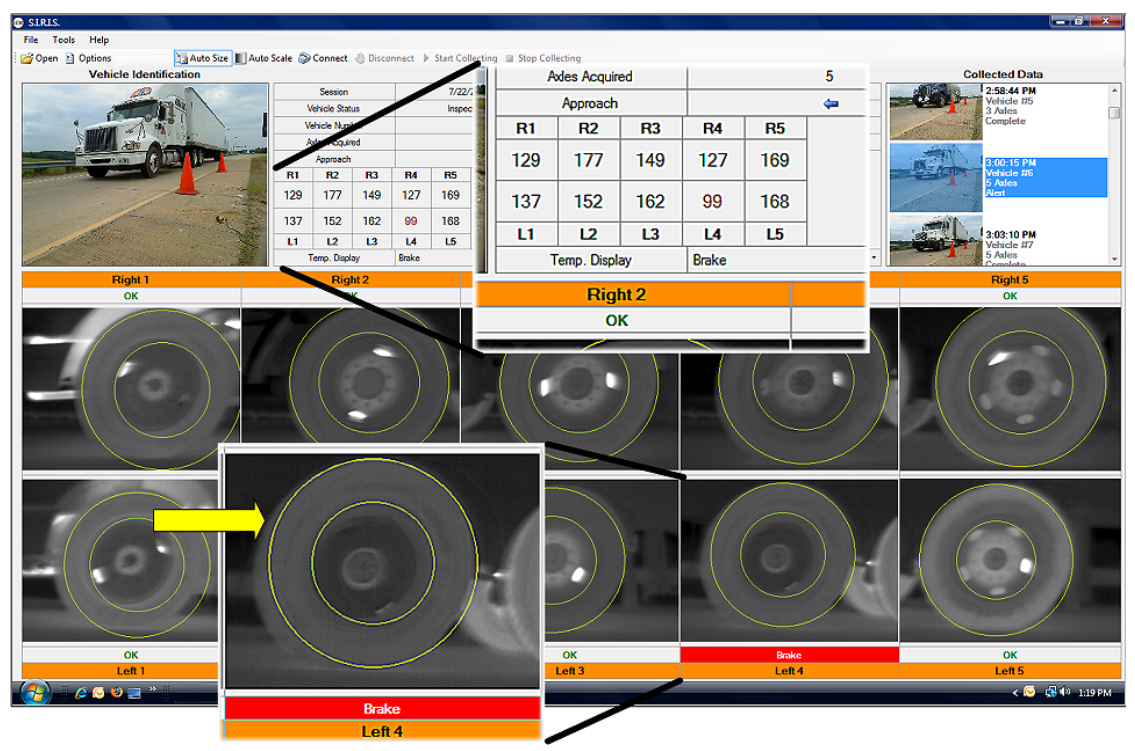

\section{RESPONSE TO AN ALERT}

When an alert occurs, the operator should follow these steps to determine if this vehicle needs to be flagged for further inspection.

1. Note what component (tire, brake, or bearing) has triggered the alert.

2. Look at the Regions of Interest. Are the regions correct? (i.e. yellow circle is around tire - see section of manual about Regions of Interest)

3. If the Regions of Interest are not correct, the alert should be ignored.

4. If the Regions of Interest are correct, the operator should choose the proper component from the Temperature Display Menu.

5. The operator should look at the temperature of the wheel that is noted with the red bar below or above it.

6. The differences in the temperatures should be analyzed. For further information on analyzing the temperature differences and how to interpret them, see the Tire Alerts, Brake Alerts, or Bearing Alerts sections of this manual.

For every vehicle that is sent for further inspection, a SIRIS report should be issued. The operator should print the screen that shows the alarm issued and the temperature data for the flagged component. This report should be physically attached to the inspection record for that vehicle. 


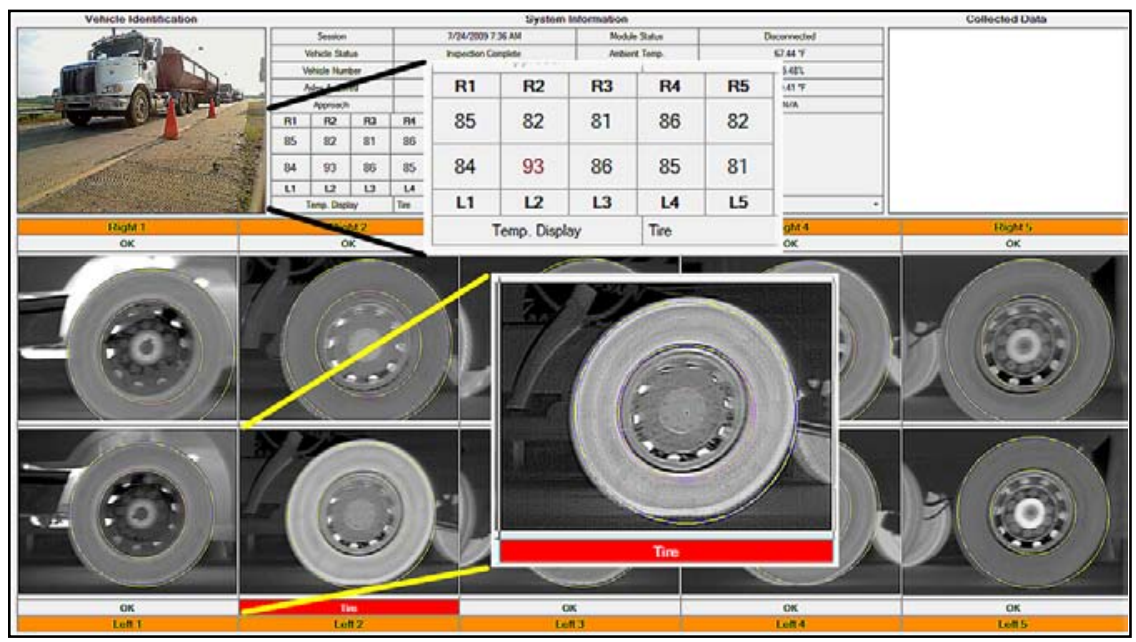

\section{TIRE ALERTS}

As a vehicle passes through the SIRIS system, each outside tire on each axle is imaged for its temperature. SIRIS will issue an alert when the tire temperature is greater than a predefined limit above ambient. The audible signal will sound and the orange bars will flash above and below the image display. The red bar will appear above or below the problem tire with the word "Tire”.

Once the alert has been issued, the operator should view the temperature information for that tire. A flat or underinflated tire will measure as hotter than the rest due to friction with the road surface as in the figure above. In the example above, the temperature of the flagged wheel is warmer than the other tires. Additionally, the image of this flat tire is brighter than the other tires.

Before flagging the vehicle for further inspection, the operator should view the image of the tire, check the ambient temperature as recorded on the user interface, and view the vehicle itself. Some possible causes of a hot wheel are: a flat, underinflated, overinflated tire; overweight or oversized vehicles; unbalanced loads; suspension issues; mechanical problems; or tread condition.

Once the operator has looked over the available data, the vehicle may be sent for a Level 2 inspection. The inspector should inspect the tire for which the alert was issued, the inside tire on the axle and that side (if one exists), the tire(s) on the opposite side of that axle, the tire in front of the tire for which that alert was issued and the tire behind it. By inspecting the tires that are opposite or around the tire that is flagged, the inspector can determine if the hot wheel is caused by a disproportion of the vehicle's weight or other issue.

It should be noted that oversized and overweight vehicles can cause overheating of the tires. This is not normally an issue. The operator should use his/her discretion when viewing the images and thermal data to make a decision about whether to flag for further inspection. 


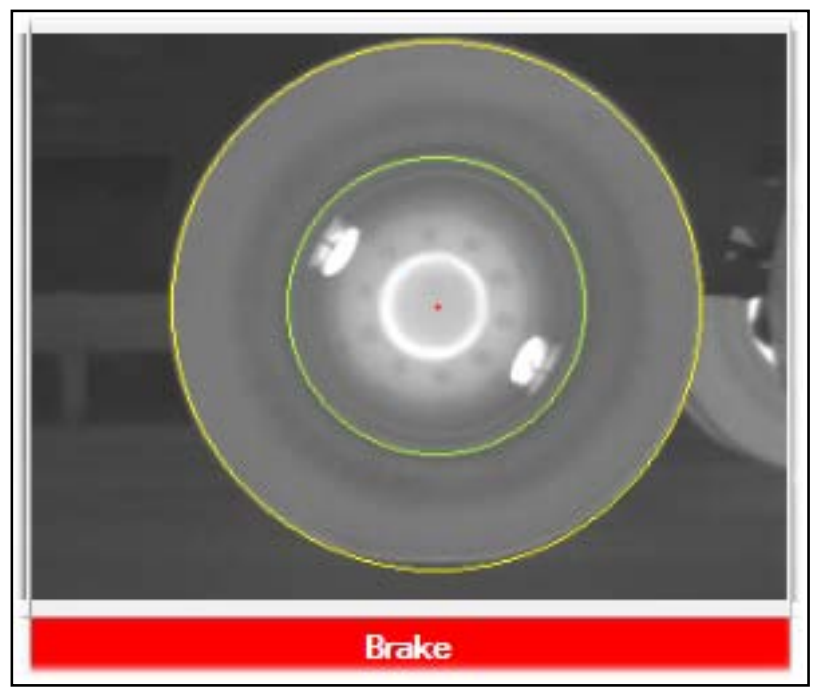

\section{BRAKE ALERTS}

Brakes are responsible for a majority of the alerts issued by SIRIS (this could vary by site and environment) and are an important safety issue for trucks, buses and other large vehicles.

When a vehicle passes through the system, SIRIS measures the temperature of the brakes through the rim. The brakes are compared to the criteria set for SIRIS and an alert can be issued for a hot or cold brake.

\begin{tabular}{|c|c|c|c|c|}
\hline R1 & R2 & R3 & R4 & R5 \\
\hline 138 & 112 & 112 & 144 & 118 \\
\hline 96 & 109 & 111 & 192 & 124 \\
\hline L1 & L2 & L3 & L4 & L5 \\
\hline \multicolumn{3}{|c|}{ Temp. Display } & \multicolumn{2}{|l|}{ Brake } \\
\hline
\end{tabular}

Hot brakes can be caused by many different circumstances including but not limited to dragging brake components, air system defects, mechanical errors, failure of opposite brake, or driving preference. Cold brakes can also be caused by some of the same conditions including but not limited to suspension, mechanical or air supply issues; inoperative or out of adjustment; or incorrect or missing attachments.

When a brake alert is issued, the operator should view the screen and the temperature data for the brakes. (S)He should view not only the brake temperature for the side that has been flagged but the information for the brake on the opposite side of that axle. A brake on one side could be hotter due to an inoperative or faulty brake on the other side. 


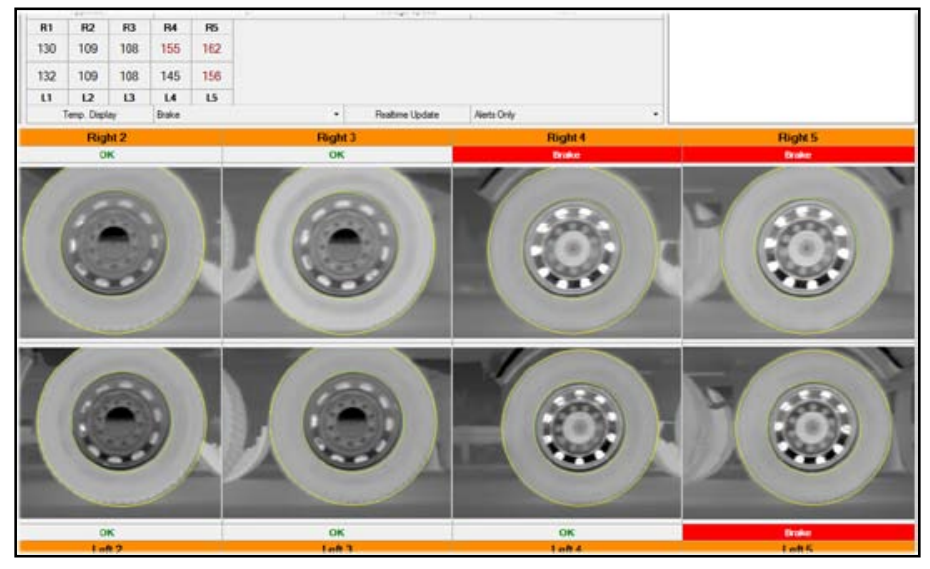

It is recommended that vehicles with brake alerts be sent for a Level 1 inspection. There are exceptions to this where the operator can see that the alert is not a true brake problem. These exceptions can be seen in certain patterns, explained below, that show a driver preference instead of a brake error.

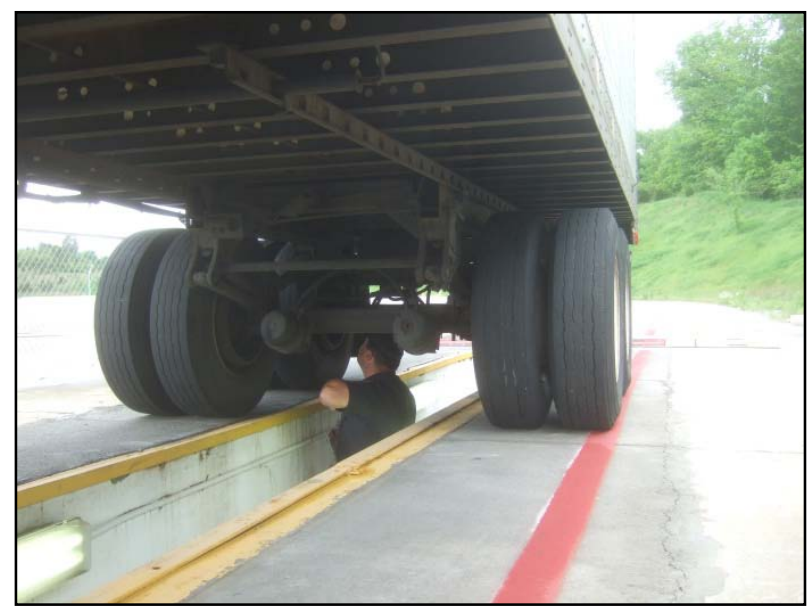


As the operator views the images and thermal data following an alert, (s)he should look for patterns which may indicate a false alert. The following situations will cause SIRIS to issue an alert but are not a brake problem.

- All four trailer brakes are flagged as hot - This is generally caused by the driver using only the trailer brake to slow the vehicle.

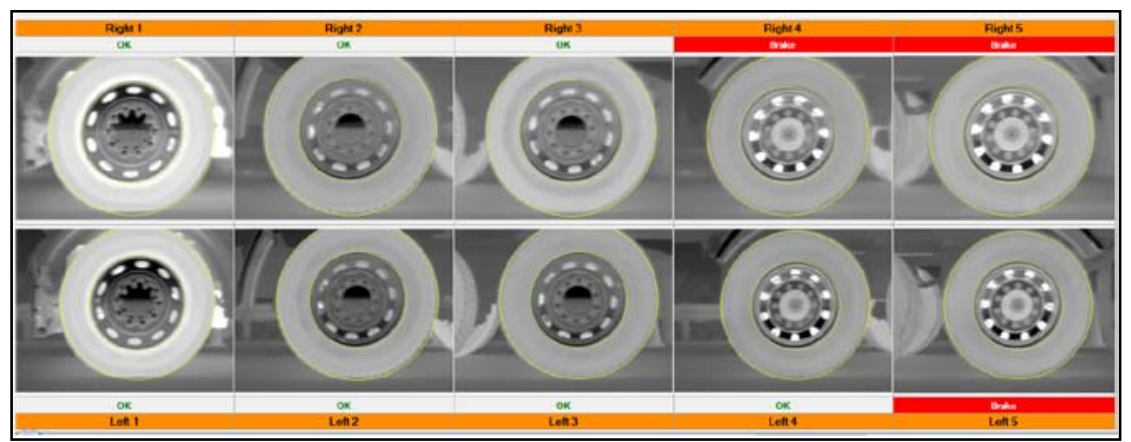

- All brakes are colder as compared to ambient - This may indicate that the vehicle has just started on its journey and has not yet applied the brakes enough to heat them up.

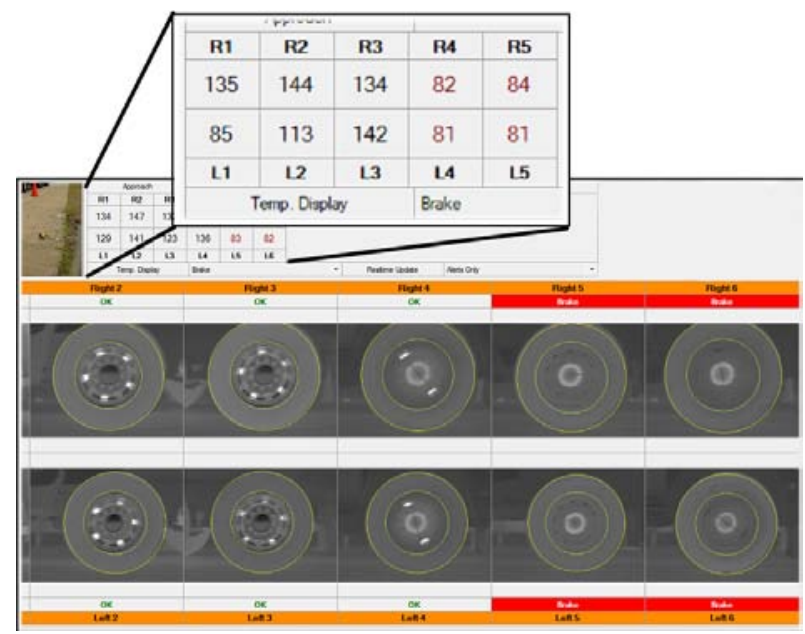

- All four trailer brakes are flagged as cold - The driver may be using the Jake Brake. This is using the engine to slow the vehicle.

It should be noted that all or most of the trailer brakes flagged as cold could also indicate that the trailer is not properly connected to the tractor. 


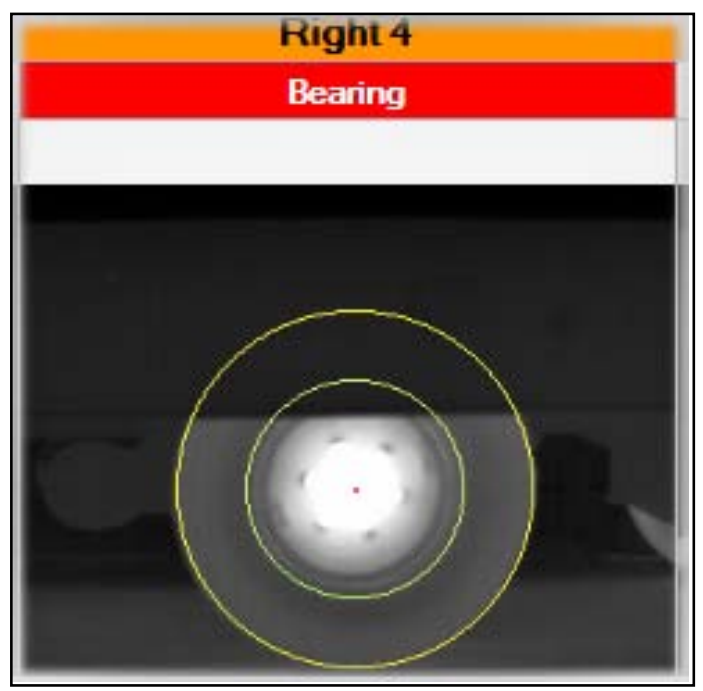

\section{BEARING ALERTS}

Bearing alerts are issued when the temperature at the Hub of the wheel is found to be above the governing criteria. Hot Bearings could be caused by leaking fluid or missing hardware. It is possible for a bearing alert to be caused by a hot brake whose thermal heat has bled into the hub area where the bearing temperature data is gathered. Bearing alerts should be sent for further inspection. A thermal gun, if available, can be used to measure the temperature of the bearing area for each wheel for comparison. The bearing housing should be checked for oil leaks, cracks and any other physical evidence of possible bearing failure. 


\section{MAINTENANCE}

All maintenance activities described below should be followed to prevent damage to the system and to ensure that the system is kept in good working order for proper operation. Before performing any maintenance or operation of SIRIS, personnel should be trained by IEM in the proper usage and maintenance of the system. There are no user serviceable parts inside of the main unit, cameras, or other casings. Do not access any of these areas unless instructed by IEM service personnel.

\section{CLEANING LENSES}

If indicated, the lenses should be wiped clean with a lint free cloth. If there is dirt that is not removed by the cloth, contact IEM for advice on solutions that can be used.

\section{RAIN OR SNOW OBSTRUCTIONS}

As in cleaning lenses above, the lenses should be wiped with a lint free cloth to remove excessive water or collected snow.

The Optical trigger should be checked after a snowfall or heavy rain to be sure that the lenses are clean and are not obstructed. Be sure to check both components which are located across the lane from each other.

\section{OPTICAL TRIGGER OBSTRUCTIONS}

The optical trigger should be checked periodically to be sure that there are no obstructions. The beam must be able to be broadcast from one sensor to the other without impediment in order for the system to operate correctly. 